\title{
1 The deletion of GluK2 alters cholinergic control of neuronal
}

2 excitability

3 Adam Gorlewicz ${ }^{1,2,3}$, Gael Barthet ${ }^{1,2}$, Stefano Zucca ${ }^{1,2}$, Peggy Vincent ${ }^{1,2}$, Marilena

4 Griguoli $^{1,2}$, Noëlle Grosjean ${ }^{1,2}$, Grzegorz Wilczynski $^{3}$, Christophe Mulle $^{1,2 *}$

$5 \quad{ }^{1}$ Interdisciplinary Institute for Neuroscience, CNRS UMR 5297

$6 \quad{ }^{2}$ University of Bordeaux, F-33000 Bordeaux, France

$7 \quad{ }^{3}$ Laboratory of Molecular and Systemic Neuromorphology, Nencki Institute of Experimental

8 Biology, Warsaw, Poland

9 Number of pages 26 Number of figures: 10;

10 Number of words, abstract: 136 ; introduction: 519

contact email address: christophe.mulle@u-bordeaux.fr

Running title: The deletion of GluK2 alters cholinergic control of neuronal excitability.

Keywords:

14

Hippocampus, Kainate receptors, Kv7/M-current, muscarinic acetylcholine receptors. 
Kainate receptors (KARs) are key regulators of synaptic circuits by acting at pre- and postsynaptic sites through either ionotropic or metabotropic actions. KARs can be activated by kainate, a potent neurotoxin, which induces acute convulsions. Here we report that the acute convulsive effect of kainate mostly depends on GluK2/GluK5 containing KARs. In contrast, the acute convulsive activity of pilocarpine and pentylenetetrazol is not alleviated in the absence of KARs. Unexpectedly, the genetic inactivation of GluK2 rather confers increased susceptibility to acute pilocarpine-induced seizures. The mechanism involves an enhanced excitability of GluK2 ${ }^{-/-}$CA3 pyramidal cells compared to controls upon pilocarpine application. Finally, we uncover that the absence of GluK2 increases pilocarpine modulation of Kv7/M currents. Taken together our findings reveal that GluK2-containing KARs can control the excitability of hippocampal circuits through interaction with the neuromodulatory cholinergic system. 


\section{INTRODUCTION}

Kainate receptors (KARs), which belong to the family of ionotropic glutamate receptors alongside AMPA and NMDA receptors, are widely expressed in the brain (Contractor et al. 2011). Five KAR subunits (GluK1, GluK2, GluK3, GluK4 and GluK5) co-assemble in various combinations to form functional homomeric and heteromeric receptors (Contractor et al. 2011; Lerma and Marques 2013). KARs regulate the activity of neuronal circuits by a variety of mechanisms which depend on subunit composition, cell-specific expression, pre- or postsynaptic localization, and signaling pathways (Mulle and Crépel 2021; Lerma and Marques 2013). These diverse roles modulate synaptic transmission and the balance between excitation and inhibition in the hippocampus, hence the overal activity of synaptic circuits (Carta et al. 2014).

KARs were initially defined by their high affinity for kainate (Bettler and Mulle 1995), a potent neurotoxin. Systemic or intracerebral administration of kainate, an agonist of AMPARs and KARs, acutely induces behavioral and electrophysiological seizures reminiscent of those found in patients with temporal lobe epilepsy (TLE) (for review see Traynelis et al. 2010; Crépel and Mulle 2015). In TLE, the most common form of human epilepsy, recurrent partial seizures originate from mesial structures such as the hippocampus and propagate to the other limbic constituents, finally giving rise to general convulsions (status epilepticus) (Bertram 2009). Although the acute seizures triggered by kainate may have been fruitful for the understanding of epileptogenesis and the discovery of antiepileptic drugs, these do not closely match the complex features of chronic seizures in TLE (Rogawski 2006). GluK2-containing KARs, which are widely expressed in the brain represent the main target for kainate-induced acute seizures (Mulle et al. 1998a). The role of GluK1 in epileptogenesis is less clear. There is evidence that GluK1 agonists act as anticonvulsants by activation of interneurons (Khalilov et al. 2002), and conversely, evidence that GluK1 antagonists may prevent seizures in a pilocarpine model of TLE. Recently, the use of GluK $1^{-/-}$mice has clearly indicated a role for this subunit in acute seizures induced by systemic administration of the potent GluK1 agonist ATPA, but not of kainate or pentylenetetrazol (PTZ) (Fritsch et al. 2014). To clarify the role of KAR subunits in the generation of acute seizures, we have systematically examined the propensity to acute seizure generation of kainate in knock-out mice for GluK1, GluK2, GluK3 and GluK5.

Other pharmacological models have utilized systemic administration of convulsive agents such as pilocarpine, a cholinergic agonist, and PTZ, a GABAergic antagonist to induce acute seizures reminiscent of status epilepticus in TLE in the rodent (Löscher et al. 1991; Lévesque et al. 2016). Here we asked whether KARs were also involved in the convulsive action of PTZ and pilocarpine. The analysis of KAR subunit knock-out mice indicates that acute behavioral seizures do not depend on KARs in these models. Our work leads to the unexpected finding 
66 that $\mathrm{GluK2}^{-/-}$mice show enhanced susceptibility to pilocarpine-induced acute seizures. We 67 then performed electrophysiological experiments to better understand the mechanisms linking 68 KARs and increased neuronal excitability induced by bath application of pilocarpine in 69 hippocampal slices. We provide further evidence that the deletion of GluK2 alters the 70 cholinergic control of excitability through inhibition of Kv7/M-currents. 


\section{MATERIALS AND METHODS}

Animals. Experimental procedures followed standard international regulation (European Commission Directive 86/609/EEC), as well as the recommendations of the CNRS ethics committee, and the French Ministry of Agriculture and Forestry concerning animal care. Wildtype mice and mutant littermates were derived from heterozygote crossings of GluK $1^{-/-}$(Mulle et al. 2000), GluK2 ${ }^{-/-}$(Mulle et al. 1998a), GluK3 ${ }^{-/-}$(Pinheiro et al. 2007), GluK5 ${ }^{-/-}$(Contractor et al. 2003) and Thy1-GFP $M$ line mice (Jackson Laboratories). GluK2 ${ }^{-/-}$mice were backcrossed on a C57BL6 and on a FVB background. The GluK1 ${ }^{-/-}$, GluK3 ${ }^{-/-}$, and GluK5 $5^{-/-}$ mice were backcrossed on a C57BL6 background. Thy1-GFP ${ }^{-/+}$were backcrossed on C57BL6 background. GluK2-floxed mice were generated in the lab of Anis Contractor (Marshall et al. 2018).

Viral gene transfer and stereotaxic delivery. Mice (P22-P30) were anesthetized by isoflurane inhalation and systemically injected with buprenorphine $(0.2 \mathrm{mg} / \mathrm{kg})$ to prevent post-surgery pain. $200 \mathrm{nl}$ of viral solution (1x 10E8 particles) was injected using a micropump and syringe (Nanofil WPI) at the rate of $100 \mathrm{nl} / \mathrm{min}$ in the CA3 (Y: $2.2 \mathrm{~mm}$ from lambda; X: $\pm 2.5 \mathrm{~mm}$ from sagittal suture; Z: $2.35 \mathrm{~mm}$ from the skull) to infect GCs. The spreading of viruses allowed the infection of a large part of the hippocampus (radius of roughly $1 \mathrm{~mm}$ ) to produce numerous slices for electrophysiology. Experiments were performed at least 2 weeks post-injection.

Kainate injection. Adult male mice (8-12 weeks old) were intraperitoneally injected with kainic acid dissolved in distilled water $\left(\mathrm{dH}_{2} \mathrm{O}\right)(20 \mathrm{mg} / \mathrm{kg})$ (Tocris). After kainate administration, each animal was assigned to one of the following stages depending on the severity of behavioral symptoms. The response scale was modified from the seizure scale developed by Racine (Racine 1972) for the pharmacological kindling model. Stage 0: no observable effect; Stage 1: immobility and rigidity, stretching of the body, tail stiffness, bulging eyes; Stage 2: repetitive shaking of the head, circular movements; Stage 3: falling, non-continuous tonic-clonic seizures with periods of total immobility; Stage 4: continuous tonic-clonic seizures, loss of posture control; Stage 5: death.

Pilocarpine injection. Adult male mice (8-12 week old) were injected intraperitoneally with a single dose of methylscopolamine nitrate dissolved in $\mathrm{dH}_{2} \mathrm{O}(1 \mathrm{mg} / \mathrm{kg})$ (Sigma-Aldrich) (Turski et al. 1984) to block the peripheral effects of pilocarpine. Twenty minutes after the methylscopolamine administration, a single dose of pilocarpine hydrochloride dissolved in $\mathrm{dH}_{2} \mathrm{O}$ (Sigma-Aldrich) was injected intraperitoneally $(200 \mathrm{mg} / \mathrm{kg}, 265 \mathrm{mg} / \mathrm{kg} 300 \mathrm{mg} / \mathrm{kg}$ or $320 \mathrm{mg} / \mathrm{kg}$, depending on the genetic background of the animal and type of the experiment). Animals were observed continuously for 3 hours after pilocarpine administration. Typically within 45 minutes after pilocarpine administration the animals experienced different symptoms of convulsions that were classified using a staging system adopted and modified from the 
Racine scale (Racine 1972). Stage 0: no observable effect; Stage 1: immobility and rigidity, repetitive shaking of the head; Stage 2: bilateral clonus of forelimbs, stretching of the body, salivation, chewing; Stage 3: non-continuous tonic-clonic seizures with periods of total immobility; Stage 4; continuous tonic-clonic seizures, loss of posture control; Stage 5: death. Time to the beginning of status epilepticus was measured, as well as the number of fatalities. The onset of status epilepticus was defined as the occurrence of continuous tonic-clonic activity (stage 4). PTZ injection. Seizures were induced in 8-12 weeks old male mice by the intraperitoneal injection of 45 or $55 \mathrm{mg} / \mathrm{kg}$ of PTZ dissolved in $\mathrm{dH}_{2} \mathrm{O}$ (Tocris) (Löscher et al. 1991). Within 15 minutes after drug administration animals experienced varied convulsive symptoms. Depending on the symptoms, each of the animals was classified to one of the following stages that were adopted and modified from the Racine scale (Racine 1972): Stage 0: no observable effect; Stage 1: reduced motor activity; Stage 2: partial clonic activity affecting the face, head, vibrissae and forelimbs, jerks of the head and forelimbs, vocalization; Stage 3: whole body clonus without loss of upright posture; Stage 4: whole body clonus with loss of upright posture; Stage 5: whole body clonus with complete loss of motoric control, wild running and jumping; Stage 6 maximal tonic-clonic seizure with tonic extension of hind limbs; Stage 7: death. Preparation of hippocampal brain slices. For electrophysiology recordings parasagittal brain slices (350 $\mu \mathrm{m}$ thick) were obtained from 19-24 days old male mice by cutting in an aqueous solution ( $\mathrm{dH}_{2} \mathrm{O}$ ) containing the following (in $\mathrm{mM}$ ): $80 \mathrm{NaCl}, 2.5 \mathrm{KCl}, 25 \mathrm{NaHCO}_{3}, 1.5 \mathrm{NaH}_{2} \mathrm{PO}_{4}$, $7 \mathrm{MgCl}_{2}, 0.5 \mathrm{CaCl}_{2}, 10$ glucose, and 75 sucrose and equilibrated with $95 \% \mathrm{O}_{2}$ and $5 \% \mathrm{CO}_{2}$. The slices were then incubated at $33^{\circ} \mathrm{C}$ for $30 \mathrm{~min}$ and subsequently stored at room temperature in an aqueous $\left(\mathrm{dH}_{2} 0\right)$ solution composed of (in $\mathrm{mM}$ ): $125 \mathrm{NaCl}, 2.5 \mathrm{KCl}, 1.25$ $\mathrm{NaH}_{2} \mathrm{PO}_{4}, 25 \mathrm{NaHCO}_{3}, 2 \mathrm{CaCl}_{2}, 1 \mathrm{MgCl}_{2}, 11$ glucose (equilibrated with $95 \% \mathrm{O}_{2}$ and $5 \% \mathrm{CO}_{2}$ ). Fluoro-Jade staining. Male mice (8-12 weeks old) were intraperitoneally injected with pilocarpine dissolved in $\mathrm{dH}_{2} \mathrm{O}(200 \mathrm{mg} / \mathrm{kg}$ or $265 \mathrm{mg} / \mathrm{kg})$ as described above, and $24 \mathrm{~h}$ after pilocarpine administration, the mice were subjected to the following Fluoro-Jade (Millipore) staining protocol. First, mice were perfused transcardially with $4 \%$ PFA solution in $0.01 \mathrm{M}$ PBS and then the brains were dissected and cut with a vibratome (40 $\mu \mathrm{m}$-thick slices). Sections were mounted onto gelatin-coated slides (Menzel-Gläser) and allowed to dry at room temperature (RT). Slides were then placed into a staining rack and immersed in $80 \% \mathrm{EtOH}$ (in $\mathrm{dH}_{2} 0$ ) with $1 \% \mathrm{NaOH}$ (in $\mathrm{dH}_{2}$ ) for 5 minutes; into $70 \% \mathrm{EtOH}$ (in $\mathrm{dH}_{2} 0$ ) for 2 minutes; into distilled water $\left(\mathrm{dH}_{2} \mathrm{O}\right)$ for 1 minute; into a solution of $0.06 \%$ potassium permanganate (in $\mathrm{dH}_{2} \mathrm{O}$ ) for $15 \mathrm{~min}$; $\mathrm{dH}_{2} \mathrm{O}$ for $2 \mathrm{~min}$. In the dark, slides were then immersed in a $0.001 \%$ Fluoro-Jade (in $\mathrm{dH}_{2} \mathrm{O}$ ) staining solution for $30 \mathrm{~min}$; rinsed $3 \mathrm{x}$ in $\mathrm{dH}_{2} \mathrm{O}$ for $1 \mathrm{~min}$; and finally dried at $50^{\circ} \mathrm{C}$.

143 Dried slides were at the end rinsed with $100 \%$ xylene for 2 min to clear, immersed in Eukitt (Sigma-Aldrich) mounting medium and coverslipped. 
Whole-cell patch clamp recordings in hippocampal brain slices. Borosilicate pipettes (Harvard apparatus) were pulled with a micropipette puller (P97, Sutter Instruments, Novato, CA). Whole-cell current clamp recordings (3-4.5 $\mathrm{M} \Omega$ electrodes filled with aqueous $\left(\mathrm{dH}_{2} \mathrm{O}\right)$ intracellular solution (in mM): $140 \mathrm{~K}$-methanesulphonate, $2 \mathrm{MgCl}$, 10 HEPES, 0.3 EGTA, 2 MgATP, 0.3 NaGTP, pH 7.3), and whole-cell voltage clamp recordings (3-4.5 $\mathrm{M} \Omega$ electrodes filled with an aqueous (in $\mathrm{dH}_{2}$ ) solution containing (in $\mathrm{mM}$ ): $\mathrm{KCl} 140$, Hepes 10, EGTA 1, MgATP 2, $\mathrm{MgCl} 22$, pH 7.3 ) were made from hippocampal CA3 pyramidal cells. The osmolality of the internal solutions was $280-290 \mathrm{mOsm} / \mathrm{l}$. Cells were visualized with infrared video-microscopy. Experiments were performed with an extracellular solution near physiological temperature $\left(33^{\circ} \mathrm{C}\right)$. No continuous current was injected to keep $\mathrm{Vm}$ around the same value during continuous current-clamp recordings. To have homogenous and comparable data sets, cells were rejected from the analysis if the initial Vm value was below $60 \mathrm{mV}$ or above $-70 \mathrm{mV}$. To investigate the action potential firing patterns of neurons, $200 \mathrm{~ms}$ depolarizing current steps from $0 \mathrm{pA}$ to $100 \mathrm{pA}$ in increments of $10 \mathrm{pA}$ were applied. The number of action potentials released at each current step was plotted against the amplitude of the current applied. The resting membrane potential (RMP) was averaged over the first $10 \mathrm{~s}$ of the 30-minute continuous current clamp recording, or over a $100 \mathrm{~ms}$ baseline preceding hyperpolarizing current steps. Spike after potentials i.e., after-hyperpolarizations (AHPs) and after-depolarizations (ADPs) were measured as the difference $(\Delta \mathrm{Vm})$ between the membrane potentials $100 \mathrm{~ms}$ before AP (initial $\mathrm{Vm}$ : $\mathrm{iVm}$ ) and either $+10 \mathrm{~ms}$ or $+100 \mathrm{~ms}$ after the peak of the AP. The $\Delta \mathrm{Vm}$, analyzed based on spontaneous APs (Fig. 6A) was correlated with the RMP measured $10 \mathrm{~ms}$ prior to AP generation (initial $\mathrm{Vm}$ ). The $\Delta \mathrm{Vm}$ values were either binned (2 $\mathrm{mV}$ bin) according to the initial $\mathrm{Vm}$ value, and averaged within a bin, or average cell by cell independent of initial $\mathrm{Vm}$ (Fig. 6E, F). To compare input resistance over different sets of data, the steady-state voltage responses were plotted against the amplitude of injected current and the slope of the linear fit of this relationship was characterized by ' $\mathrm{R}^{2}$ ' (coefficient of determination) and ' $\mathrm{a}$ ' (linear regression coefficient). To record $\mathrm{M}$-currents $\left(\mathrm{I}_{\mathrm{M}}\right), \mathrm{NaH}_{2} \mathrm{PO}_{4}$ was omitted from the extracellular solution. To minimize contamination with other voltage-dependent conductances, IM was recorded in the presence of TTX $(1 \mu \mathrm{M}), \mathrm{ZD} 7288(20 \mu \mathrm{M})$ and $\mathrm{CdCl}_{2}(500 \mu \mathrm{M})$ to block $\mathrm{Na}^{+}$, $\mathrm{I}_{\mathrm{h}}, \mathrm{Ca}^{2+}$ and $\mathrm{Ca}^{2+}$-dependent $\mathrm{K}^{+}$currents, respectively. Xe991 $\left(50 \mu \mathrm{M}\right.$, dissolved in $\left.\mathrm{dH}_{2} 0\right)$ was present in some experiments in order to block Kv7.2/7.3 channels. Capacitance was continuously monitored by applying $10 \mathrm{mV}$ pulses from a holding potential of $-70 \mathrm{mV}$. To minimize voltage errors in voltage-clamp recordings, this was usually compensated by 75 $80 \%$. If series resistance changed $>20 \%$ during the experiments, the data were discarded. Measurements of membrane potentials were not corrected for liquid junction potential error. For $I_{M}$ deactivation a series of 10 voltage commands ( $5 \mathrm{mV}$ increment) from the holding 
potential of $-20 \mathrm{mV}$ was applied. The M-current downregulation was measured as the difference between the initial $(<10 \mathrm{~ms})$ and sustained (>100 ms) current of the current trace in control conditions minus the difference calculated alike upon XE991 or pilocarpine treatment. Immunofluorescence. Fluorescent immunohistochemistry was performed in $50-\mu m$-thick, freefloating cryosections of perfusion-fixed (4\% PFA in 0.01M PBS) brains which were obtained from 8-12 weeks old male mice. The brain sections were subjected to 30-minute incubation with 5\% normal donkey serum (NDS) (Jackson Laboratories) and 0.2\% Triton X-100 (Sigma) dissolved in $\mathrm{dH}_{2} \mathrm{O}$ at $\mathrm{RT}$, followed by overnight incubation with primary antibody diluted in aqueous solutions (in $\mathrm{dH}_{2} \mathrm{O}$ ) of $5 \%$ NDS with $0.2 \%$ Triton at $4^{\circ} \mathrm{C}$. The detection of immunoreactions was performed using species-specific secondary antibodies directly conjugated to fluorophores (two-hour incubation at RT). Secondary antibodies were diluted in $5 \%$ NDS (in $\mathrm{dH}_{2} \mathrm{O}$ ) with $0.5 \%$ Triton (in $\mathrm{dH}_{2} \mathrm{O}$ ). After incubation with secondary antibodies samples were rinsed with $0.01 \mathrm{M}$ PBS, dried on coverslips, immersed in mounting medium and coverslipped. The following primary antibodies and their dilutions were used: rabbit antiGluK2/K3 (clone NL9, Labome, 04-921) (1:100) and rabbit anti KCNQ2 (Invitrogen, PA1-929) (1:100). The following secondary antibodies were used: donkey anti-rabbit (1:200) conjugated to Alexa555 (Invitrogen).

Data acquisition and analysis. Whole-cell patch clamp recordings were made using an EPC 9 or EPC 10 amplifier (HEKA Electronik), data were filtered at $3 \mathrm{kHz}$ with a Bessel filter, and digitized at $10 \mathrm{kHz}$. Off-line data analysis was performed using IGOR PRO (WaveMetrics), and Matlab (MathWorks). Data were acquired with pClamp (Molecular Devices), digitized at 10 $\mathrm{kHz}$, filtered at $3 \mathrm{kHz}$, and analyzed off-line with built in Clampfit (Molecular Devices) functions. All images were acquired with Leica DM5000 fluorescent microscope (Leica), or NanoZoomer scanner (Hamamatsu). For final inspection, the images were processed using Corel Package as well as standard functions, of the ImageJ program.

For the calculation of the number of Fluoro-Jade positive neurons, stacks of $z$ - planes were maximum-projected with ImageJ (National Institutes of Health, Bethesda, Maryland, USA), and single plane images were subjected to the analysis with the Matlab (MathWorks) script. The algorithm used in the script contained the following steps: automatic threshold-based binaryzation, distance transform, and watershed-based segmentation of the objects, erosion/dilation operation for removal of the isolated pixels, and finally object labelling. Regional fluorescence intensities of KAR and Kv7.2 immunoreactivities were calculated in maximum projected 8-bit images with ImageJ built-in functions. 3D rendering of processed stacks was done using 3DViewer plugin of ImageJ software. 3D models presenting colocalization of Kv7.2 immunoreactivity with giant mossy fiber boutons and thorny excrescence were created using Blender software (Blender foundation). 
218 MS Excel (Microsoft), Matlab (Math Works) and Prism (GraphPad Software Inc.) were used

219 for data management and statistics. To test whether the data follow standard normal

220 distribution we used one-sample Kolmogorov-Smirnov test. To test the null hypothesis that

221 data sets are from populations with the same distribution we used two-sample Kolmogorov-

222 Smirnov test (KS). Either parametric t-test or nonparametric Mann-Whitney U test (MW) were

223 performed to test the null hypothesis that mean values may come from the two data sets with

224 the same distribution. The two-way ANOVA was used to compare the mean differences

225 between the two populations of neurons when analyzing excitability (the number of spikes and

226 respective current step were used as group factors) and when comparing the mean difference

227 between the two populations of neurons when analyzing spike after potentials relationship to

228 membrane potential prior to the peak of the spike. Values are given as means \pm S.E.M. $p<0.05$

229 was considered statistically significant. Asterisk notation was used in order to flag the levels of

230 significance $\left(p>0.05 ;{ }^{*} p \leq 0.05 ;{ }^{* *} p \leq 0.01 ;{ }^{* * *} p \leq 0.001 ;{ }^{* * * *} p \leq 0.0001\right)$.

231 For preparation of figures images were processed with Corel Package (Corel Corporation) and

232 MS PowerPoint (Microsoft). 


\section{RESULTS}

\section{The convulsive effects of kainate depend on specific KAR subunits}

In the hippocampus, activation of GluK2-containing KARs with low concentrations of kainate acutely enhances the excitability of CA3 pyramidal neurons leading to the generation and propagation of seizures (Mulle et al. 1998a). We first examined which KAR subunits account for kainate-induced convulsive activity by exploring the sensitivity of mouse mutants for GluK1, GluK2, GluK3 and GluK5. The insensitivity of GluK2 $2^{-/-}$mice to kainate was previously reported using mice with a mixed C57BI6/129Sv background (Mulle et al. 1998a). Here, GluK2 ${ }^{-/-}$mice were backcrossed on two different backgrounds for more than 10 generations (C57BI6 and FVB) to test whether the insensitivity of $\mathrm{GluK}^{-1-}$ mice to kainate depends on the genetic background. Mice ( $n=6-10)$ were injected intraperitoneally with kainate $(20 \mathrm{mg} / \mathrm{kg})$. The acute behavioral manifestation of seizure was classified following a modification of the seizure scale developed by Racine (Racine 1972) ranging from 0 when no observable effect was noted, to 5 when the seizure was lethal. We observed a strong resistance to kainate administration in GluK2 $^{-/}$and GluK5 ${ }^{-1-}$ mice as indicated by the plots of the distribution of responses (Fig. 1A). Moreover, the effect of kainate did not depend on the genetic background since GluK2-- mice on both the FVB and C57BI6 backgrounds were similarly resistant to the proconvulsant (Fig. 1A). Moreover, kainate administration in GluK $1^{-/-}$and GluK3 ${ }^{-1-}$ animals induced acute seizures to an extent which was not significantly different from control mice, indicating that these two subunits do not participate in kainate-induced acute seizures (Fig. 1A).

\section{GluK2 $^{-/-}$mice show increased susceptibility to pilocarpine-induced acute seizures}

The fact that kainate acts through high affinity KARs to generate kainate-induced seizures is however expected. Whether KARs participate in other models of acute seizures in which KARs are not directly targeted by the convulsant has however not been fully characterized. We evaluated the sensitivity of the mutant mice in two common models of acute seizures in rodents, following injection of pilocarpine, a cholinergic muscarinic receptor agonist (Turski et al. 1984) and PTZ, a GABA $A$ receptor antagonist (Squires et al. 1984). We performed intraperitoneal injections of pilocarpine $(265 \mathrm{mg} / \mathrm{kg}$ for the FVB background and $320 \mathrm{mg} / \mathrm{kg}$ for the C57BI6 background) and PTZ (45 mg/kg for the FVB background and $55 \mathrm{mg} / \mathrm{kg}$ for the C57BI6 background) and classified the severity of the acute behavioral responses to the convulsants. The necessity to use two different doses of both drugs resulted from the differential sensitivity of mice with different backgrounds (Löscher et al. 2017). The doses of pilocarpine and PTZ suitable for an optimal effect in C57BI6-based strains were too high in the case of FVB mice, causing intense seizures and high mortality. In order to obtain conclusive data we reduced the doses of convulsants as indicated. We did not find any significant difference in the sensitivity of GluK1 $1^{-/}$, GluK3 ${ }^{-/-}$, and GluK5 ${ }^{-/-}$mice to pilocarpine $(n=6-16)$ (Fig. 
1B). Unexpectedly, GluK2 ${ }^{-/}$mice were more prone to the convulsant effect of pilocarpine than the respective littermate control mice (Fig. 1B). Moreover, we found that the increased susceptibility of GluK2-- was selective for pilocarpine. Indeed, PTZ-treated GluK2 ${ }^{-{ }^{-}}(n=6-12)$ did not demonstrate any significant difference in their response to the convulsant when compared to control mice on both FVB and C57BI6 backgrounds. Genetic deletion of GluK1, GluK3 or GluK5 did not alter the severity of PTZ-induced seizures (Fig. 1C) when compared to littermate controls $(n=7)$. To further investigate the increased sensitivity of $\mathrm{GluK2}^{--}$mice to pilocarpine, we monitored the behavior of $\mathrm{GluK2}^{+/+}$and GluK2-/- FVB mice during 120 minutes following injection of pilocarpine ( $265 \mathrm{mg} / \mathrm{kg}$ intraperitoneally). Mice which developed at least stage 3 seizures were further analyzed ( $n=9-10)$. Typically, 2-3 very short episodes (several seconds) of tonic-clonic seizures (stage 3) were observed, eventually giving way to continuous limbic motor seizures with intense salivation, rearing, clonus, and falling (stage 4 -status epilepticus) (Fig. 2A). GluK2${ }^{1-}$ mice experienced the first short episode of tonic-clonic seizure much earlier than GluK2 ${ }^{+/+}$ mice (12.5 \pm 2 min for GluK2 ${ }^{-/}$, and 19 \pm 2 min for GluK2 $\left.{ }^{+/+}, \mathrm{p}<0.05\right)$ (Fig. 2B1). Similarly, GluK2 I- mice developed status epilepticus much earlier than GluK2 ${ }^{+/+}$mice $(18 \pm 4$ min for GluK2-/-, and $26 \pm 2$ min for GluK2 ${ }^{+/+}, \mathrm{p}<0.05$ ) (Fig. 2B1). The fraction of $\mathrm{GluK2}^{-{ }^{-}}$mice that survived and recovered after status epilepticus was lower (10\%) than for GluK2 ${ }^{+/+}$mice (70\%) (Fig. 2B2). Importantly, a lower dose of pilocarpine $(200 \mathrm{mg} / \mathrm{kg})$ which did not induce any observable stage 3 or 4 seizures in control mice, was efficient in triggering epileptiform convulsions in GluK2 $2^{-/-}$ mice (26 \pm 6 min to the first clonic-tonic episode, and $35 \pm 5$ min to status epilepticus) (Fig. 2B1). Hence, in the pilopcarpine model of epilepsy GluK2 KARs appear to play a paradoxical protective role, since its absence renders mice more susceptible to seizure induction. Excessive activation of neurons through ionotropic glutamate receptors, including KARs, can cause generalized neuronal damage (excitotoxicity) in vitro in primary cultures, as well as in vivo (Vincent and Mulle 2009). CA3 pyramidal neurons and hilar interneurons are amongst the most vulnerable to network hyperactivity and readily degenerate following overexcitation (Wang et al. 2008). We tested whether the enhanced susceptibility of GluK2-/- FVB mice to pilocarpine was reflected in excitotoxic lesions in the hippocampus following pilocarpine administration. Brain sections from both control $(n=12)$ and $\mathrm{GluK}^{-/-}(n=12)$ mice were stained with Fluoro-Jade (a fluorescein-derived fluorochrome which selectively stains damaged neurons) $24 \mathrm{~h}$ after pilocarpine administration. We observed that pilocarpine $(200 \mathrm{mg} / \mathrm{kg})$ induced neuronal death in the hippocampus of $\mathrm{GluK}^{-/-}$mice as indicated by the numerous Fluoro-Jade positive cells in different hippocampal subregions (Fig. 2C). In contrast, FluoroJade staining was hardly detectable in the same regions in $\mathrm{GluK2}^{+/+}$hippocampal sections (density of Fluoro-Jade positive cells per $\mathrm{mm}^{3}$ in hilus: $6646.4 \pm 1420$ for GluK2 ${ }^{-/-}$and $530.5 \pm 202$ for GluK2 $2^{++}, p<0,001$; in DG: $2834.5 \pm 671$ for GluK2 $2^{-/}$and $645 \pm 25$ for GluK2 $2^{+/+}, p<0,001$; in 
CA3: $3391 \pm 1152$ for GluK2 ${ }^{-/}$and $74 \pm 42$ for GluK2 ${ }^{+/+}, p<0,001$; in CA2: $4681 \pm 1725$ for GluK2 I- and $67 \pm 38.5$ for GluK2 ${ }^{+/+}$; in CA1: $3785 \pm 925$ for GluK2 ${ }^{+/+}$and $113 \pm 30$ for GluK2 ${ }^{+/+}, p<0,001$ (graph in Fig. 2C). In convergence with behavioral observations, this demonstrates that the effect of pilocarpine is enhanced in GluK2 ${ }^{-/-}$mice.

\section{Enhanced excitation of CA3 pyramidal neurons by pilocarpine in $\mathrm{GluK2}^{-1-}$ mice}

Considering the important role of GluK2-containing KARs in regulating firing, excitability, and synaptic properties of CA3 pyramidal neurons, we postulated that the increased susceptibility to pilocarpine-induced status epilepticus in $\mathrm{GluK}^{-/-}$mice may be related to an altered response of CA3 pyramidal neurons to pilocarpine. To explore this possibility we performed currentclamp recordings from CA3 pyramidal cells in control and GluK2 ${ }^{-/-}$brain slices from FVB mice and examined the effects of pilocarpine application on membrane potential and neuronal activity. In control slices $(n=5)$, addition of pilocarpine $(30 \mu M)$ resulted in the depolarization of CA3 pyramidal cells (from $-67 \pm 1 \mathrm{mV}$ to $-62 \pm 2 \mathrm{mV} 20$ minutes following pilocarpine application in the bath, $p<0.001$ ) (Fig. S1). Addition of atropine suppressed the depolarization induced by pilocarpine confirming that it was mediated by muscarinic acetylcholine receptors (data not shown). To compare the effect of pilocarpine on depolarization in GluK2 ${ }^{+/+}$and $\mathrm{GluK}^{-/} \mathrm{CA} 3$ neurons, the concentration of pilocarpine was reduced from $30 \mu \mathrm{M}$ to $10 \mu \mathrm{M}$ due to a large depolarization and quick deterioration of membrane properties in $\mathrm{GluK}^{-{ }^{-}}$neurons upon $30 \mu \mathrm{M}$ pilocarpine treatment. Addition of $10 \mu \mathrm{M}$ pilocarpine caused a statistically significant depolarization of GluK2 $^{--}$CA3 neurons $(n=10)$ but the membrane potential change at this pilocarpine concentration was not significant in GluK2 ${ }^{+/+}$CA3 neurons $(n=10)$ (from $-68 \pm 1 \mathrm{mV}$ to $-65 \pm 1 \mathrm{mV}$ for GluK2 ${ }^{+/+}$and from $-68 \pm 1 \mathrm{mV}$ to $-58 \pm 1 \mathrm{mV}$ for GluK2 ${ }^{-/}, \mathrm{p}<0.001$ ) (Fig. 3A) and a robust firing of the CA3 cells. In an effort to investigate whether this phenomenon was cell autonomous, we invalidated GluK2 gene specifically in CA3 cells by viral delivery of the Cre recombinase to CA3 region of GluK2-floxed (GluK2fl) mice (CA3-cKO). First, we isolated the synaptic currents mediated by KARs in CA3 cells by stimulating mossy fibers at $3 \mathrm{~Hz}$ under condition where AMPAR-mediated currents are inhibited by LY303070 (Fig. 3B). We observed a total abolition of KAR-mediated currents in CA3-cKO cells (Cre-positive GFP reporting) compared to controls (GFP positive) cells (Fig. 3C) indicating the loss of GluK2 from Cre expressing CA3 pyramidal cells. We then compared responses of CA3 pyramidal cells to hyperpolarizing and depolarizing current steps before (no pilocarpine in the bath) and 20 minutes after pilocarpine $(10 \mu \mathrm{M})$ addition (Fig. 3D). We observed that application of pilocarpine resulted in a higher firing rate in CA3-cKO cells $(n=10)$ in comparison to control ( $n=10)$ CA3 pyramidal cells $(12 \pm 10$ and $27 \pm 23 \mathrm{~Hz}$ at $100 \mathrm{pA}$ for control and CA3-cKO cells respectively, $p<0.001$ ) (Fig. 3E). The hyperpolarization induced by steps of negative current was significantly larger upon pilocarpine application (Fig.3F). This observation is consistent 
with the well-known modulation of cationic conductance by M1 muscarinic receptor activated by pilocarpine. Remarkably, whereas the levels of hyperpolarization were not statistically different between control and CA3-cKO pyramidal cells in control condition, a robust difference appears between the two genotypes upon pilocarpine application (-35 and -68 mV at -100 pA for GluK2 ${ }^{+/+}$and GluK2 $2^{-/}$respectively, p<0.001) (Fig. 3F). Accordingly, the input resistance was increased by application of pilocarpine in both genotypes (Fig. 3G) but the effect was stronger in CA3-cKO cells compared to control CA3 pyramidal cells (343 and $669 \mathrm{MOhm}$ in GluK2 ${ }^{+/+}$ and GluK2 $^{-/-}$respectively). This increased membrane resistance likely participates in the increased excitability of CA3 pyramidal cells because the firing rate induced by depolarizing current steps in the presence of pilocarpine was higher in CA3-cKO cells even when the initial membrane voltage was held at $-70 \mathrm{mV}$ in both genotypes (Fig. S2).Taken together our data indicate that pilocarpine induces a stronger effect on membrane potential and input resistance in CA3 pyramidal cells in the absence of GluK2 containing KARs. This uncovers a functional interaction between membrane conductance modulation by muscarinic receptors and KARs, which regulates the excitability of CA3 pyramidal cells. The convulsive action of pilocarpine likely depends on the activation of M1 muscarinic receptordependent pathways (Hamilton et al. 1997). Therefore, we tested whether the observed difference in depolarization of CA3 pyramidal cells in response to pilocarpine between genotypes was directly dependent on cholinergic signaling pathways or whether this was an indirect consequence of a general change in the excitability of CA3 pyramidal cells. We recorded the activity of CA3 pyramidal cells in GluK2 ${ }^{+/+}$and GluK2 ${ }^{-/-}$brain slices from FVB mice and tested the effects of gradually increasing $\mathrm{K}^{+}$concentration in the ACSF (from $2.5 \mathrm{mM}$ to $7.5 \mathrm{mM}$ ). As expected, increased $\mathrm{K}^{+}$concentration progressively led to depolarization of CA3 pyramidal cells in GluK2 ${ }^{++}(n=10)$ and GluK2 ${ }^{-/}(n=11)$ slices (Fig. S3). There was no difference in the membrane potential change between the genotypes 20 minutes after ACSF exchange (from $-63 \mathrm{mV} \pm 1.0 \mathrm{mV}$ to $-53 \pm 1.0 \mathrm{mV}$ for $\mathrm{GluK2}^{+/+}$and from $-65 \pm 1.0 \mathrm{mV}$ to $-53 \pm 1.0 \mathrm{mV}$ for GluK2 ${ }^{\prime}$ ) (Fig. S3). Moreover, we did not note any difference in the number of action potentials generated by a depolarizing pulse in the presence of $7.5 \mathrm{mM} \mathrm{K}^{+}(2.6 \pm 0.5$ spikes/200 ms at 100 pA for GluK2+/+ $(n=10)$ and $3.0 \pm 1$ spikes/200 ms at 100 pA step for GluK2 $\left.{ }^{-/}(n=11)\right)$ (Fig.4A, traces and top graphs). The I/V relation during hyperpolarizing current steps application was linear and no significant difference was observed in average input resistance of recorded GluK2 $^{-/} \quad(n=11)$ and GluK2 ${ }^{++}(n=10)$ neurons in control conditions $\left(R^{2}=0.991 \pm 0.0043\right.$, $a=340 \pm 22$ for GluK2$^{+/+}$and $\mathrm{R}^{2}=0.996 \pm 0.0043, a=303 \pm 22$ for $\mathrm{GluK}^{-{ }^{-}}$) and when high $\mathrm{K}^{+}$ concentration was present in the ACSF $\left(R^{2}=0.979 \pm 0.0101\right.$, $a=223 \pm 13$ for $\mathrm{GluK}^{+/+}$and $\mathrm{R}^{2}=$ $0.995 \pm 0.0009, a=259 \pm 27$ for GluK2 ${ }^{--}$) (Fig. 4A, bottom graphs). 
It has been shown that neuronal excitability and intrinsic bursting in hippocampal pyramidal neurons is tightly regulated by the density of low voltage-activated, non-inactivating $\mathrm{K}^{+}$current (Kv7/M-current) (Brown and Adams 1980; Halliwell and Adams 1982; Yue and Yaari 2004, 2006). Kv7/M-current ( $\left.I_{M}\right)$ flows through M-type channels (KCNQ/M-channels) composed of homo- or heteromeric tetramers of five Kv7 (Kv7.1-7.5) subunits encoded by the KCNQ gene family. Kv7.2 and Kv7.3 are the major components of the M-type channel (Shah et al. 2002). $I_{M}$ is inhibited through muscarinic receptor activation by acetylcholine and cholinomimetic drugs such as pilocarpine. We thus tested the hypothesis that the observed increase in neuronal excitability in CA3 pyramidal neurons, and the enhanced sensitivity to pilocarpine administration in GluK2 $^{-/-}$mice, may all be explained by the modulation of inhibition of $\mathrm{I}_{\mathrm{M}}$ by GluK2-containing KARs.

For this, we first performed whole cell voltage clamp recordings from CA3 pyramidal cells of GluK2 ${ }^{+/+}$FVB mice in the presence of TTX $(1 \mu \mathrm{M}), \mathrm{ZD} 7288(20 \mu \mathrm{M})$ and $\mathrm{CdCl}_{2}(500 \mu \mathrm{M})$ to pharmacologically suppress $I_{M}$-unrelated voltage-dependent conductances. The addition of Xe991 (50 $\mu \mathrm{M})$, a potent Kv7.2/7.3 channel blocker, allowed to reveal the $I_{\mathrm{M}}$. Prior to, and twenty minutes after the administration of Xe991 in the bath, we applied a series of 10 voltage steps (5 mV increment) from the holding potential of $-20 \mathrm{mV}$ (Brown and Adams 1980) (Fig. $5 \mathrm{~A}$-top traces). The voltage steps elicited slow current relaxations representing the voltage dependent deactivation of $I_{M}$. These slow $I_{M}$ currents were reduced by addition of $50 \mu \mathrm{M}$ of Xe991 (Fig. 5A bottom traces and graphs; from $116 \pm 21 \mathrm{pA}$ at $-25 \mathrm{mV}$ in control conditions $(n=10)$ to $61.5 \pm 6.5 \mathrm{pA}$ at $-25 \mathrm{mV}, \mathrm{p}<0.001,20$ minutes after Xe991 application $(n=10))$, indicating successful pharmacological isolation of $I_{M}$. We then investigated the amplitude of $I_{M}$ currents measured as the current subtraction between control and in presence of $10 \mu \mathrm{M}$ pilocarpine (20 minutes after the drug addition) in GluK2 ${ }^{+/+}$versus $\mathrm{GluK2}^{-/-}$cells. Voltage dependent deactivation of $I_{M}$ was not different in GluK2 ${ }^{+++}(n=11)$ and GluK2 $2^{-/-}(n=10)$ CA3 pyramidal cells in control conditions (mean current amplitude $113 \pm 18 \mathrm{pA}$ at $-25 \mathrm{mV}$ for GluK2 ${ }^{+/+}$ and $98 \pm 10 \mathrm{pA}$ at $-25 \mathrm{mV}$ for GluK2 ${ }^{-1}$ ) (Fig. 5B -top graph and Fig. 5C -top graph and traces). However we observed that the $I_{M}$ currents were significantly inhibited by pilocarpine at a concentration of $10 \mu \mathrm{M}$ in GluK2 ${ }^{---}(n=10)$ neurons (from $98 \pm 10 \mathrm{pA}$ to $61 \pm 13 \mathrm{pA}$ at $-25 \mathrm{mV}$ ), however the same concentration of pilocarpine has not been potent enough to significantly affect GluK2 $^{++}(n=9)$ neurons (from 113 \pm 18 pA to $101 \pm 21$ pA $-25 \mathrm{mV}$ ) (Fig. 5B -bottom graph and Fig. $5 \mathrm{C}$-bottom graph and traces). Overall this experiment indicates that the cholinergic inhibition of $I_{M}$ in CA3 pyramidal neurons is negatively modulated by GluK2-containing KARs.

\section{Altered spike after potentials in GluK2 ${ }^{-/-}$cells after pilocarpine administration}

Slowly activating outward $\mathrm{K}^{+}$currents like $\mathrm{I}_{\mathrm{M}}$ act as a 'brake' on repetitive action potential discharges and, as such, regulate the excitability of various central and peripheral neurons 
(Delmas and Brown 2005). In hippocampal principal cells $I_{M}$ currents contribute to the spike after potentials i.e. after-hyperpolarizations (AHPs) and after-depolarizations (ADPs) (Yue and Yaari 2004; Caspi et al., 2009; Mateos-Aparicio et al., 2014). We thus tested the impact of GluK2 deletion on spike after potentials measured at $+10 \mathrm{~ms}$ (ADP) and $+100 \mathrm{~ms}$ (medium AHP, mAHP) after the spike in the presence of pilocarpine $(10 \mu \mathrm{M})$. The amplitude of the ADP and mAHP depends on the membrane potential at which the APs are generated (initial Vm: $\mathrm{iVm}$ ) (see Figure 6A). Here we based our analysis on spontaneous APs recorded in control and CA3-cKO pyramidal cells in the presence of pilocarpine. We first isolated spontaneous spikes regardless of the $\mathrm{i} \mathrm{m}$ and measured $\Delta \mathrm{Vm}$ (change in $\mathrm{Vm}$ ) at $+10 \mathrm{~ms}$ and $+100 \mathrm{~ms}$ after the spike and averaged the value for each cell. We observed that in control conditions $\Delta \mathrm{Vm}$ was higher in CA3-cKO cells at $+10 \mathrm{~ms}$ (representing a larger ADP) (WT:2.6 $\pm 3.3 \mathrm{mV}$; cKO $5.9 \pm 2.6 \mathrm{mV} ; \mathrm{p}=0.04$ ) (Figure $6 \mathrm{~B}-\mathrm{C}$ ). Moreover, the $\Delta \mathrm{Vm}$ was lower than zero at $+100 \mathrm{~ms}$ (mAHP) only in WT condition but not in cKO. (WT: $-1.4 \pm 1.0, p=0.002$; cKO $-0.5 \pm 1.3$ ) (Figure $6 \mathrm{~B}, \mathrm{D})$. We then measured $\Delta \mathrm{Vm}$ in reference to initial $\mathrm{Vm}$, and we binned the values of $\Delta \mathrm{Vm}$ from all cells within a genotype according to the initial $\mathrm{Vm}(2 \mathrm{mV}$ bins) (Figure 6D). This provided a complex relationship showing that in control CA3 pyramidal cells, the ADP was revealed when the $\mathrm{iVm}$ ranged between -60 and $-55 \mathrm{mV}$ (Figure $6 \mathrm{E}$ ), and the $\mathrm{mAHP}$ was mainly observed with depolarized $\mathrm{Vm}$ (initial $\mathrm{Vm}$ above $-45 \mathrm{mV}$ ) (Figure $\mathrm{F}$ ). The relationship between $\Delta \mathrm{Vm}$ and initial $\mathrm{Vm}$ was markedly different in CA3-cKO pyramidal cells (Figure 6E, F). First, the ADP was present and consistently larger than in control CA3 pyramidal cells for initial Vm above - $55 \mathrm{mV}$. Second, a consistent mAHP was not observed in CA3-cKO pyramidal cells whatever the initial Vm (Figure 6F). The combination of enhanced ADP and reduced mAHP can explain the increased excitability of CA3 pyramidal cells with selective deletion of GluK2 in the presence of pilocarpine.

In order to complement these functional observations, we tested whether Kv7.2, a constituent of KCNQ/M-channels, was co-expressed with GluK2 in CA3 pyramidal cells. We analyzed the immunohistochemical distribution of GluK2 and Kv7.2 using antibodies (GluK2/K3 and Kv7.2 respectively) which have been previously tested for their specificity (Wyeth et al. 2014; Jenkins et al. 2015; Straub et al. 2016; Pablo and Pitt 2017). The experiment was conducted on brain sections from Thy1-GFP mice (Thy1-GFP-M) (Feng et al. 2000) which express GFP in sparse subsets of neurons within specific populations and have proven useful for labeling particular projections including mossy fibers. As expected, GluK2/K3 immunoreactivity was observed almost exclusively in the stratum lucidum (Fig. 7A, top panels). The GluK2/K3-related fluorescence intensity observed in brain sections $(n=6)$ was on average $2.4 \pm 0.3$ folds higher in the stratum lucidum than in the stratum radiatum (Fig. 7A, top panels and graph). Kv7.2 immunoreactivity was high in the pyramidal cell layer of analyzed sections $(n=6)$ but was also 
clearly observed in stratum lucidum (Fig. 7A, bottom panels and graph). The pre- and postsynaptic compartments of mossy fiber synapses can be resolved using GFP fluorescence as a volume marker (Feng et al. 2000). Subsequent confocal microscopy revealed immunoreactivity for Kv7.2 in both giant mossy fiber boutons and in the postsynaptic thorny excrescence in CA3 pyramidal (Fig. 7B), indicating that GluK2-containing KARs and Mchannels colocalize at mossy fiber synapses.

457

458

459

460

461

462

463

464

465

466

467

468

469

470

471

472

473

474

475

476

\section{DISCUSSION}

The acute administration of the neurotoxin kainate has long been known to trigger behavioural and electrophysiological seizures (Ben-Ari and Cossart 2000). Kainate administration in rodents has helped understanding the physiology of seizures and has been fruitful for the discovery of antiepileptic drugs (Rogawski 2006). However the fact that kainate is a high affinity ligand for KARs (Bettler and Mulle 1995) does not necessarily imply that KARs are involved in the complex etiology of TLE (Crépel and Mulle 2015). This work was initially designed to address the role of the different KAR subunits in the action of different convulsant drugs with distinct mechanisms of action. We demonstrate that none of the KAR subunits tested promote acute epileptic discharges induced by pilocarpine and by PTZ, two convulsants used to model acute epileptogenic activity (Turski et al. 1984; Löscher et al. 1991). Unexpectedly, we found that deletion of the GluK2 subunit increases the sensitivity to pilocarpine-induced seizures. Our results indicate that GluK2-containing KARs control the excitation of CA3 pyramidal cells induced by the muscarinic agonist pilocarpine by controlling the inactivation of KCNQ/Mcurrents and its role in shaping the spike afterpolarization (ADP and mAHP). The demonstration that GluK2/K3 and Kv7.2 immunoreactivity co-compartmentalizes at mossy fiber synapses further suggests a functional association between GluK2-containing KARs and pathways modulating $\mathrm{KCNQ} / \mathrm{M}$ currents.

Our results first confirm that GluK2-containing KARs represent the main target for acute epileptic seizures induced by kainate (Mulle et al. 1998a). Because mouse strains differ from one another in their susceptibility to the actions of convulsants (Ferraro et al. 1995) and to seizure-induced excitotoxic cell death (Schauwecker 2012), we have tested pilocarpine and other chemoconvulsants in two different mouse genetic backgrounds for GluK2 deletion, in the C57BI6 and FVB backgrounds. Our results indicate that GluK2 is the main target of the chemoconvulsant kainate independently of the genetic backgrounds. Our experiments also exclude GluK1 and GluK3 as epileptogenic targets of kainate (Fritsch et al. 2014). Likewise, it has been reported that the proconvulsant activity of systemic ATPA (a selective GluK1 agonist), but not of AMPA or kainate, is mediated by GluK1-containing KARs (Fritsch et al. 2014). The epileptogenic action of kainate can likely be attributed to a direct depolarization of principal neurons in the hippocampus and neocortex by activation of GluK2-containing KARs 
(Mulle et al. 1998b; Bureau et al. 1999; Beed et al. 2009). Moreover, our data contribute to the demonstration that kainate likely targets GluK2/GluK5 KARs, the main KAR subtype in the brain (Wenthold et al. 1994). The GluK5 subunit conveys high affinity to kainate in heteromeric KARs (Bettler and Mulle 1995; Contractor et al. 2003), and is likely an obligatory component of GluK2-containing KARs in the hippocampus.

We found that genetically removing GluK1, GluK2, GluK3 or GluK5 neither prevented acute seizures triggered by the systemic administration of pilocarpine, which predominantly targets M1 muscarinic acetylcholine receptors, nor PTZ, which targets $\mathrm{GABA}_{\mathrm{A}}$ receptors. Similarly, deletion of GluK1 or GluK2 does not elevate the threshold for acute seizures in the olfactory bulb kindling model (Fritsch et al. 2014). It should be stressed however, that GluK2/GluK5 KARs play a major role in recurrent epileptic seizures in the pilocarpine model of chronic TLE (Peret et al. 2014; Matsuda et al. 2016), albeit these receptors are not necessarily involved in the initial epileptogenic events. The involvement of aberrant synaptic GluK2/GluK5 KARs at recurrent mossy fiber synapses onto dentate gyrus cells has been clearly identified as a central mechanism for chronic epileptic discharges (Epsztein et al. 2005, 2010; Peret et al. 2014). Interestingly, even though GluK2 $2^{-/-}$mice display a markedly higher susceptibility to acute seizures induced by systemic pilocarpine administration, GluK2 ${ }^{-/-}$mice are protected against chronic seizures in the pilocarpine mouse model of TLE (Peret et al. 2014). This clearly indicates a disconnection between the facilitating role of KARs in the acute convulsant activity of pilocarpine, and the involvement of GluK2/GluK5 KARs in chronic epilepsy which relies on long-term reorganization of mossy fibers and which promote recurrent seizures reminiscent of TLE (Epsztein et al. 2005, 2010; Peret et al. 2014). Along these lines, it is worth mentioning that the genetic deletion of GluK2 does not prevent mossy fiber sprouting in the pilocarpine mouse model of chronic TLE. Overall, it is important to clarify that our data do not indicate any involvement of the cholinergic modulation of hippocampal neurons by GluK2 in TLE. The higher susceptibility to acute seizures induced by systemic pilocarpine administration in GluK2 $^{-/-}$mice was documented by the lower doses necessary to induce acute seizures and by the shorter latency to behavioural manifestations of seizures. Considering the relevance for CA3 in triggering epileptic discharges (Reyes-Garcia et al. 2018) and the major role played by GluK2-containing KARs in CA3 pyramidal cells (Carta et al. 2014), we directly analyzed the impact of pilocarpine administration on the activity of individual CA3 pyramidal cells in brain slices. Application of pilocarpine $(10 \mu \mathrm{M})$ in rat hippocampal slices triggers brief $(200 \mathrm{~ms})$ interictal-like activity, as well as more prolonged synchronous neuronal activity comparable to acute seizure-like discharges characterized by depolarizing CA3 pyramidal cells (Nagao et al. 1996; Rutecki and Yang 1998). Both synaptic and non-synaptic events appear to account for the generation of acute seizure-like discharges by pilocarpine (Rutecki and Yang 1998). In CA3 pyramidal cells recorded in a slice preparation, muscarinic receptor activation supports 
persistent firing (Jochems and Yoshida 2013) and modulates glutamatergic transmission either directly or indirectly through depolarization and spike discharges in CA3 interneurons and dentate gyrus cells (Vogt and Regehr 2001). Consistent with studies describing the phasic and tonic activation of muscarinic receptors by acetylcholine in CA3, (Dasari and Gulledge 2011) pilocarpine evoked a gradual depolarization of CA3 pyramidal cells associated with an increased frequency of action potentials. These effects were markedly potentiated in slices from GluK2 $2^{-/}$mice as well as in CA3 pyramidal with cell specific deletion of GluK2. Acetylcholine-mediated regulation of CA3 excitability is mainly mediated by M1 muscarinic receptors (Dasari and Gulledge 2011), a primary target for pilocarpine. Hence muscarinic regulation of excitability in CA3 is under the control of GluK2-containing KARs. We further extended the analysis using conditional KO mice (Marshall et al., 2018) to show that selective removal of GluK2 from CA3 pyramidal cells is sufficient to trigger hypersensitivity to pilocarpine. This demonstrates that the interaction between M1 muscarinic receptors and KARs is a cell autonomous effect taking place in CA3 pyramidal cells and does not rely on indirect network interactions.

539 To get further insight into the mechanisms of this crosstalk between KARs and muscarinic receptor pathways, we studied $\mathrm{Kv} 7 / \mathrm{M}$-currents, non-inactivating $\mathrm{K}^{+}$currents which are the main player in mediating the effects of M1 muscarinic receptor activation in neurons (Brown and Adams 1980; Hamilton et al. 1997; Shapiro et al. 2000), and in controlling neuronal activity in the hippocampus. Suppression of Kv7/M-currents has deleterious effects on neuronal excitability by initiating a transition from physiological network activity to temporal lobe seizure (Devaux et al. 2004; Qiu et al. 2007). Here we report that KARs modulate Kv7/M-currents inhibition in CA3 pyramidal neurons. Spike after polarization play (ADPs and AHPs) play an important role in the overall neuronal excitability and these are modulated by M1 muscarinic receptors through activation of KV7/M currents (Yue and Yaari 2004; Gu et al. 2005) in CA1 pyramical cells. We found that in the presence of pilocarpine the ADP is increased in CA3-cKO pyramidal cells, at all initial Vm from -35 to $-55 \mathrm{mV}$. Conversely, whereas the mAHP was observed for an initial $\mathrm{Vm}$ above $-45 \mathrm{mV}$ in control CA3 pyramidal cells, the mAHP was not consistently measured in CA3-cKO pyramidal cells. The conjunction of an increased ADP and a decreased $\mathrm{mAHP}$, together with an increased input resistance due to Kv7 closing (in agreement with Sun and Kapur 2012) likely participates in the hyperexcitability of CA3 pyramidal cells in the absence of GluK2. Overall GluK2-containing KARs participate in the modulation of neuronal excitability induced by cholinergic agonists in CA3 pyramidal cells. The genetic deletion of GluK2 leading to loss of control on Kv7/M-currents seems to potentiate the generation of seizures by pilocarpine within hippocampal circuits.

559 The molecular mechanisms explaining the interaction between GluK2 and muscarinic 560 pathways regulating Kv7/M-currents, and potentially between KARs and muscarinic AChRs, 
need to be elucidated. The mechanism of Kv7/M-currents inhibition by activation of M1 AChRs is indirect and requires G-protein activation through second messengers (Delmas and Brown 2005). KARs are known to exert a variety of metabotropic actions, independent of their ionotropic function (Lerma and Marques 2013). Among these actions, KARs likely comprised or GluK2/GluK5 subunits increase neuronal excitability of CA3 pyramidal cells (Fisahn 2005; Ruiz et al. 2005), by reversible inhibition of the slow $\mathrm{Ca}^{2+}$-activated $\mathrm{K}^{+}$current (slow AHP) through a G-protein-coupled mechanism. Consequently removing GluK2 (hence GluK2/GluK5) decreases KAR mediated increase in neuronal excitability (Ruiz et al. 2005; Sachidhanandam et al. 2009). Interestingly, a recent study has shown that direct application of kainate or trains of synaptic stimulation reduce the postburst AHP in pyramidal neurons of the piriform cortex through activation of GluK2-containing KARs, in control animals but not in animals which have learned a complex olfactory task (Chandra et al. 2019).

Activation of mAChRs by pilocarpine in slices significantly enhances KAR currents and excitotoxicity mediated by GluK2/GluK5 (but not homomeric GluK2), and potentiates mossy fiber axon excitability (Benveniste et al. 2010). In contrast, we observe that pilocarpine-induced increase in neuronal excitability is enhanced in the absence of GluK2, indicating that the two mechanisms are not linked. Interestingly, P2X7R knockout mice similarly show enhanced susceptibility to seizures induced by pilocarpine, despite having similar levels of hippocampal M1 mAChR expression (Kim and Kang 2011). This hypersensitivity to pilocarpine does not involve GABAergic or glutamatergic transmission, but appears to depend on a process mediated by $\mathrm{PKC}$ via intracellular $\mathrm{Ca}^{2+}$ release. Overall our data suggest that GluK2-containing KARs may act as a negative regulator of the actions of mAChRs on the excitability of neural circuits. It would certainly be important to explore the physiological conditions under which KARs and mAChRs, activated by their endogenous ligands, interact to regulate the activity of hippocampal circuits in vivo in physiological conditions.

\section{ACKNOWLEDGEMENTS}

This work was supported by the Centre National de la Recherche Scientifique, by the French ANR grant KAREP and by the National Science Center (Poland) (grant 2013/08/M/NZ3/00655). Adam Gorlewicz was partially supported by scholarship granted by the French Government and the French Embassy in Poland as well as by the National Science Center (Poland) (grant 2015/19/D/NZ7/02402). We thank Mario Carta and Christophe Blanchet for their help with electrophysiology. The microscopy was performed in the Bordeaux Imaging Center (BIC), a service unit of the CNRS-Inserm and Bordeaux University, member of the national infrastructure France Biolmaging.

\section{BIBLIOGRAPHY}


Beed PS, Salmen B, Schmitz D. 2009. GluK2-Mediated Excitability within the Superficial Layers of the Entorhinal Cortex. PLoS One. 4:e5576.

Ben-Ari Y, Cossart R. 2000. Kainate, a double agent that generates seizures: two decades of progress. Trends Neurosci. 23:580-587.

Benveniste M, Wilhelm J, Dingledine RJ, Mott DD. 2010. Subunit-dependent modulation of kainate receptors by muscarinic acetylcholine receptors. Brain Res. 1352:61-69.

Bertram EH. 2009. Temporal lobe epilepsy: where do the seizures really begin? Epilepsy Behav. 14 Suppl 1:32-37.

Bettler B, Mulle C. 1995. AMPA and kainate receptors. Neuropharmacology. 34:123-139.

Brown DA, Adams PR. 1980. Muscarinic suppression of a novel voltage-sensitive $\mathrm{K}+$ current in a vertebrate neurone. Nature. 283:673-676.

Bureau I, Bischoff S, Heinemann SF, Mulle C. 1999. Kainate receptor-mediated responses in the CA1 field of wild-type and GluR6-deficient mice. J Neurosci. 19:653-663.

Carta M, Fièvre S, Gorlewicz A, Mulle C. 2014. Kainate receptors in the hippocampus. Eur J Neurosci. 39:1835-1844.

Caspi A, Benninger F \& Yaari Y (2009). KV7/M channels mediate osmotic modulation of intrinsic neuronal excitability. J Neurosci 29, 11098-11111.

Chandra N, Awasthi R, Ozdogan T, Johenning FW, Imbrosci B, Morris G, Schmitz D, Barkai E. 2019. A cellular mechanism underlying enhanced capability for complex olfactory discrimination learning. eNeuro. 6.

Contractor A, Mulle C, Swanson GT. 2011. Kainate receptors coming of age: milestones of two decades of research. Trends Neurosci. 34:154-163.

Contractor A, Sailer AW, Darstein M, Maron C, Xu J, Swanson GT, Heinemann SF. 2003. Loss of kainate receptor-mediated heterosynaptic facilitation of mossy-fiber synapses in KA2-/- mice. J Neurosci. 23:422-429.

Crépel V, Mulle C. 2015. Physiopathology of kainate receptors in epilepsy. Curr Opin Pharmacol. 20:83-88.

Dasari S, Gulledge AT. 2011. M1 and M4 receptors modulate hippocampal pyramidal neurons. J Neurophysiol. 105:779-792.

Delmas $\mathrm{P}$, Brown D a. 2005. Pathways modulating neural KCNQ/M (Kv7) potassium channels. Nat Rev Neurosci. 6:850-862.

Devaux JJ, Kleopa KA, Cooper EC, Scherer SS. 2004. KCNQ2 Is a Nodal K+ Channel. J Neurosci. 24:1236-1244.

Epsztein J, Represa A, Jorquera I, Ben-Ari Y, Crépel V. 2005. Recurrent mossy fibers establish aberrant kainate receptor-operated synapses on granule cells from epileptic rats. J Neurosci. 25:8229-8239.

Epsztein J, Sola E, Represa A, Ben-Ari Y, Crépel V. 2010. A Selective Interplay between Aberrant EPSPKA and INaP Reduces Spike Timing Precision in Dentate Granule Cells of Epileptic Rats. Cereb Cortex. 20:898-911.

Feng G, Mellor RH, Bernstein M, Keller-Peck C, Nguyen QT, Wallace M, Nerbonne JM, 
Lichtman JW, Sanes JR. 2000. Imaging Neuronal Subsets in Transgenic Mice Expressing Multiple Spectral Variants of GFP. Neuron. 28:41-51.

Ferraro TN, Golden GT, Smith GG, Berrettini WH. 1995. Differential Susceptibility to Seizures Induced by Systemic Kainic Acid Treatment in Mature DBA/2J and C57BLI6J Mice. Epilepsia. 36:301-307.

Fisahn A. 2005. Kainate receptors and rhythmic activity in neuronal networks: hippocampal gamma oscillations as a tool. J Physiol. 562:65-72.

Fritsch B, Reis J, Gasior M, Kaminski RM, Rogawski M a. 2014. Role of GluK1 kainate receptors in seizures, epileptic discharges, and epileptogenesis. J Neurosci. 34:57655775.

Gu N, Vervaeke K, Hu H, Storm JF. 2005. Kv7/KCNQ/M and HCN/h, but not KCa2/SK channels, contribute to the somatic medium after-hyperpolarization and excitability control in CA1 hippocampal pyramidal cells. J Physiol. 566:689-715.

Halliwell J V, Adams PR. 1982. Voltage-clamp analysis of muscarinic excitation in hippocampal neurons. Brain Res. 250:71-92.

Hamilton SE, Loose MD, Qi M, Levey a I, Hille B, McKnight GS, Idzerda RL, Nathanson NM. 1997. Disruption of the $m 1$ receptor gene ablates muscarinic receptor-dependent $M$ current regulation and seizure activity in mice. Proc Natl Acad Sci U S A. 94:1331113316.

Jenkins PM, Kim N, Jones SL, Tseng WC, Svitkina TM, Yin HH, Bennett V. 2015. Giant ankyrin-G: a critical innovation in vertebrate evolution of fast and integrated neuronal signaling. Proc Natl Acad Sci U S A. 112:957-964.

Jochems A, Yoshida M. 2013. Persistent firing supported by an intrinsic cellular mechanism in hippocampal CA3 pyramidal cells. Eur J Neurosci. 38:2250-2259.

Khalilov I, Hirsch J, Cossart R, Ben-Ari Y. 2002. Paradoxical anti-epileptic effects of a GluR5 agonist of kainate receptors. J Neurophysiol. 88:523-527.

Kim J-E, Kang T-C. 2011. The P2X7 receptor-pannexin-1 complex decreases muscarinic acetylcholine receptor-mediated seizure susceptibility in mice. J Clin Invest. 121:20372047.

Lerma J, Marques JM. 2013. Kainate Receptors in Health and Disease. Neuron. 80:292311.

Lévesque M, Avoli M, Bernard C. 2016. Animal models of temporal lobe epilepsy following systemic chemoconvulsant administration. J Neurosci Methods. 260:45-52.

Löscher W, Ferland RJ, Ferraro TN. 2017. The relevance of inter- and intrastrain differences in mice and rats and their implications for models of seizures and epilepsy. Epilepsy Behav. 73:214-235.

Löscher W, Hönack D, Fassbender CP, Nolting B. 1991. The role of technical, biological and pharmacological factors in the laboratory evaluation of anticonvulsant drugs. III. Pentylenetetrazole seizure models. Epilepsy Res. 8:171-189.

Marshall JJ, Xu J, Contractor A. 2018. Kainate receptors inhibit glutamate release via mobilization of endocannabinoids in striatal direct pathway spiny projection neurons. $J$ Neurosci. 38:3901-3910. 
Martinello K, Giacalone E, Migliore M, Brown DA, Shah MM. 2019. The subthreshold-active KV7 current regulates neurotransmission by limiting spike-induced $\mathrm{Ca} 2+$ influx in hippocampal mossy fiber synaptic terminals. Commun Biol. 2.

Mateos-Aparicio P, Murphy R \& Storm JF (2014). Complementary functions of SK and Kv7/M potassium channels in excitability control and synaptic integration in rat hippocampal dentate granule cells. J Physiol (Lond) 592, 669-693.

Matsuda K, Budisantoso T, Mitakidis N, Sugaya Y, Miura E, Kakegawa W, Yamasaki M, Konno K, Uchigashima M, Abe M, Watanabe I, Kano M, Watanabe M, Sakimura K, Aricescu AR, Yuzaki M. 2016. Transsynaptic Modulation of Kainate Receptor Functions by C1q-like Proteins. Neuron. 90:752-767.

Mulle C, Sailer , Swanson GT, Brana C, O'Gorman S, Bettler B, Heinemann SF. 2000. Subunit composition of kainate receptors in hippocampal interneurons. Neuron. 28:475484.

Mulle C, Sailer A, Pérez-Otaño I, Dickinson-Anson H, Castillo PE, Bureau I, Maron C, Gage FH, Mann JR, Bettler B, Heinemann SF. 1998a. Altered synaptic physiology and reduced susceptibility to kainate- induced secures in GluR6-deficient mice. Nature. 392:601-605.

Mulle C, Sailer A, Pérez-Otaño I, Dickinson-Anson H, Castillo PE, Bureau I, Maron C, Gage FH, Mann JR, Bettler B, Heinemann SF. 1998b. Altered synaptic physiology and reduced susceptibility to kainate-induced seizures in GluR6-deficient mice. Nature. 392:601-605.

Nagao T, Alonso A, Avoli M. 1996. Epileptiform activity induced by pilocarpine in the rat hippocampal-entorhinal slice preparation. Neuroscience. 72:399-408.

Pablo JL, Pitt GS. 2017. FGF14 is a regulator of KCNQ2/3 channels. Proc Natl Acad Sci. 114:154-159.

Peret A, Christie L a., Ouedraogo DW, Gorlewicz A, Epsztein J, Mulle C, Crépel V. 2014. Contribution of Aberrant GluK2-Containing Kainate Receptors to Chronic Seizures in Temporal Lobe Epilepsy. Cell Rep. 8:347-354.

Pinheiro PS, Perrais D, Coussen F, Barhanin J, Bettler B, Mann JR, Malva JO, Heinemann SF, Mulle C. 2007. GluR7 is an essential subunit of presynaptic kainate autoreceptors at hippocampal mossy fiber synapses. Proc Natl Acad Sci U S A. 104:12181-12186.

Qiu C, Johnson BN, Tallent MK. 2007. K + M-Current Regulates the Transition to Seizures in Immature and Adult Hippocampus. Epilepsia. 48:2047-2058.

Racine RJ. 1972. Modification of seizure activity by electrical stimulation: II. Motor seizure. Electroencephalogr Clin Neurophysiol. 32:281-294.

Reyes-Garcia SZ, Scorza CA, Araújo NS, Ortiz-Villatoro NN, Jardim AP, Centeno R, Yacubian EMT, Faber J, Cavalheiro EA. 2018. Different patterns of epileptiform-like activity are generated in the sclerotic hippocampus from patients with drug-resistant temporal lobe epilepsy. Sci Rep. 8:1-15.

Rogawski M a. 2006. Molecular targets versus models for new antiepileptic drug discovery. Epilepsy Res. 68:22-28.

Ruiz A, Sachidhanandam S, Utvik JK, Coussen F, Mulle C. 2005. Distinct subunits in heteromeric kainate receptors mediate ionotropic and metabotropic function at hippocampal mossy fiber synapses. J Neurosci. 25:11710-11718. 
Rutecki PA, Yang Y. 1998. Ictal Epileptiform Activity in the CA3 Region of Hippocampal Slices Produced by Pilocarpine. J Neurophysiol. 79:3019-3029.

Sachidhanandam S, Blanchet C, Jeantet Y, Cho YH, Mulle C. 2009. Kainate receptors act as conditional amplifiers of spike transmission at hippocampal mossy fiber synapses. $\mathrm{J}$ Neurosci. 29:5000-5008.

Schauwecker PE. 2012. Strain differences in seizure-induced cell death following pilocarpine-induced status epilepticus. Neurobiol Dis. 45:297-304.

Shah MM, Mistry M, Marsh SJ, Brown D a, Delmas P. 2002. Molecular correlates of the Mcurrent in cultured rat hippocampal neurons. J Physiol. 544:29-37.

Shapiro MS, Roche JP, Kaftan EJ, Cruzblanca H, Mackie K, Hille B. 2000. Reconstitution of muscarinic modulation of the KCNQ2/KCNQ3 K(+) channels that underlie the neuronal M current. J Neurosci. 20:1710-1721.

Squires RF, Saederup E, Crawley JN, Skolnick P, Paul SM. 1984. Convulsant potencies of tetrazoles are highly correlated with actions on GABA/benzodiazepine/picrotoxin receptor complexes in brain. Life Sci. 35:1439-1444.

Straub C, Noam Y, Nomura T, Yamasaki M, Yan D, Fernandes HB, Zhang P, Howe JR, Watanabe M, Contractor A, Tomita S. 2016. Distinct Subunit Domains Govern Synaptic Stability and Specificity of the Kainate Receptor. Cell Rep. 16:531-544.

Traynelis SF, Wollmuth LP, McBain CJ, Menniti FS, Vance KM, Ogden KK, Hansen KB, Yuan H, Myers SJ, Dingledine R. 2010. Glutamate receptor ion channels: structure, regulation, and function. Pharmacol Rev. 62:405-496.

Turski WA, Cavalheiro EA, Bortolotto ZA, Mello LM, Schwarz M, Turski L. 1984. Seizures produced by pilocarpine in mice: a behavioral, electroencephalographic and morphological analysis. Brain Res. 321:237-253.

Vincent P, Mulle C. 2009. Kainate receptors in epilepsy and excitotoxicity. Neuroscience. 158:309-323.

Vogt KE, Regehr WG. 2001. Cholinergic modulation of excitatory synaptic transmission in the CA3 area of the hippocampus. J Neurosci. 21:75-83.

Wang L, Liu Y-H, Huang Y-G, Chen L-W. 2008. Time-course of neuronal death in the mouse pilocarpine model of chronic epilepsy using Fluoro-Jade $C$ staining. Brain Res. 1241:157-167.

Wenthold RJ, Trumpy VA, Zhu WS, Petralia RS. 1994. Biochemical and assembly properties of GluR6 and KA2, two members of the kainate receptor family, determined with subunit-specific antibodies. J Biol Chem. 269:1332-1339.

Wyeth MS, Pelkey KA, Petralia RS, Salter MW, McInnes RR, McBain CJ. 2014. Neto Auxiliary Protein Interactions Regulate Kainate and NMDA Receptor Subunit Localization at Mossy Fiber-CA3 Pyramidal Cell Synapses. J Neurosci. 34:622-628.

Yue C, Yaari Y. 2004. KCNQ/M Channels Control Spike Afterdepolarization and Burst Generation in Hippocampal Neurons. J Neurosci. 24:4614-4624.

Yue C, Yaari Y. 2006. Axo-Somatic and Apical Dendritic Kv7/M Channels Differentially Regulate the Intrinsic Excitability of Adult Rat CA1 Pyramidal Cells. J Neurophysiol. 95:3480-3495. 
Figure 1 - Behavioral responses to the systemic administration of proconvulsants in KAR mutant mice

A-C) Six to 16 mice representing different KAR mutants were intraperitoneally injected with kainate $(A)$, pilocarpine $(B)$, or PTZ $(C)$. For kainate and pilocarpine administration the response varied from no effect (stage 0 ) and mild manifestation (stages $1,2,3$ ) up to maximum effect (stage 4) and lethality (stage 5). For PTZ the response varied from no effect (stage 0) and mild manifestation (stages 1, 2, 3, 4, 5) up to maximum effect (stage 6) and lethality (stage 7). Note that no behavioral effect of kainate injection was observed in GluK2 and GluK5 knockout mice, independently of the genetic background for GluK2 ${ }^{-/-}$mice. On the other hand GluK2I- mice were more prone to acute behavioural seizures in response to pilocarpine administration as compared to controls and all other mutant mice. No difference was observed within KAR mutant mice in response to PTZ injection.

Figure 2 - Seizure latency, excitotoxicity, and survivability in GluK2 ${ }^{+/+}$and GluK2 ${ }^{-/-}$mice in response to systemic pilocarpine administration

A) Two control and two experimental groups (9 to 10 mice each) were injected with pilocarpine according to the scheme. B1-B2) Graphs representing the latency to the appearance of the first tonic-clonic convulsion (stage 3 seizure) and to the beginning of the status epilepticus (stage 4 seizure), as well as percentage of survivors during the experiment in both control and GluK2 $^{--}$mice. Note that application of pilocarpine $(265 \mathrm{mg} / \mathrm{kg})$ induced stage 3 and 4 seizures much faster and lead to higher mortality in GluK2 ${ }^{-/}$mice as compared to control mice (B1, left graph). When the dose of pilocarpine was reduced $(200 \mathrm{mg} / \mathrm{kg}$ ), only moderate effects (no stage 3 or 4 seizure) were observed in control mice in contrast to marked effects observed in GluK2 $^{-/-}$mice (B1, right graph). C) Fluoro-Jade positive neurons in the hippocampus of GluK2 ${ }^{+/+}$ and GluK2 $^{-/-}$mice $24 \mathrm{~h}$ after intraperitoneal pilocarpine injection. The density of Fluoro-Jade positive cells in different regions of hippocampus was calculated for both control and experimental group (graph). Note the prominent excitotoxicity caused by pilocarpine (200 $\mathrm{mg} / \mathrm{kg}$ ) in GluK2-- mice in contrast to control mice.

Figure 3 - Pilocarpine action in CA3 pyramidal cells in slices from GluK2 ${ }^{+/+}$and GluK2 ${ }^{-/-}$ mice

A) Perfusion of pilocarpine into the slice depolarized CA3 pyramidal cells. A concentration of pilocarpine $(10 \mu \mathrm{M})$ which moderately affected $\mathrm{GluK}^{+/+}$neurons (dark blue trace and graph) lead to spike discharges in GluK2 ${ }^{-/}$neurons (light blue trace and graph). B) Synaptic transmission in WT and GluK2-cKO CA3 neurons (slices from GluK2fl mice infected with viral vector harboring GFP or Cre-GFP). Left, stimulation of mossy fibers triggers EPSCs with 
amplitude increasing with frequency $(1 \mathrm{~Hz}$ vs $0.1 \mathrm{~Hz})$. Right, KAR-mediated EPSCs are isolated at $3 \mathrm{~Hz}$ (red traces). C) KAR mediated currents were not measurable in GluK2-cKO CA3 neurons. D) Hyperpolarizing and depolarizing current steps under control conditions and 20 minutes after $10 \mu \mathrm{M}$ pilocarpine addition to the bath. Pilocarpine increases spike discharge in both genotypes but the effect is greater in GluK2-cKO CA3 neurons (red traces and bottom graphs). E) The firing rate increases after pilocarpine application. This increase is larger in GluK2-cKO CA3 neurons. F) The hyperpolarizations are greater after application of pilocarpine and even larger in GluK2-cKO CA3 neurons. G) The input resistance increases after pilocarpine application. This increase is larger in GluK2-cKO CA3 neurons.

Figure 4 - Frequency of evoked action potential firing does not differ between GluK2 ${ }^{+/+}$ and GluK2 ${ }^{-1-}$ CA3 neurons under influence of increased extracellular $\mathrm{K}^{+}$levels

Application of depolarizing current steps at the beginning (control conditions) and 20 minutes after ACSF exchange did not reveal any significant difference in the frequency of action potential firing between both genotypes (traces and top graphs) and in the input resistance (bottom graphs).

\section{Figure 5 - Involvement of GluK2-containing KARs in the modulation of M-currents}
A) Voltage/current relation demonstrates the sensitivity of the recorded current to Xe991 in GluK2 $^{+/+}$cells (top traces and top graph). Xe991-mediated reduction of the current amplitude in $\mathrm{GluK}^{+/+}$cells 20 minutes after the drug application (bottom traces and bottom graph) indicates that $I_{M}$ is a significant component of the analyzed response. B) Voltage-dependent deactivation of the $I_{M}$ did not differ significantly between $\mathrm{GluK}^{+/+}$and $\mathrm{GluK}^{-/-}$neurons in control conditions (top graph). However, $10 \mu \mathrm{M}$ pilocarpine significantly inhibited $\mathrm{I}_{\mathrm{M}}$ in GluK2 ${ }^{-/-}$ neurons but not in $\mathrm{GluK}^{+/+}$neurons (bottom graph) 20 minutes after the drug application. $\mathrm{C}$ ) Pilocarpine-mediated effect on the $I_{M}$ current amplitude 20 minutes after the drug application to $\mathrm{GluK}^{+/+}$(top traces and graph) and GluK2 ${ }^{-/-}$cells (bottom traces and graph).

\section{Figure 6 - Altered spike after potentials in GluK2 $^{-/-}$cells after pilocarpine administration} A) Representative spontaneous AP recorded from CA3 pyramidal cell at -60 (left) or -50 (right) $\mathrm{mV}$. The dotted lines extend the membrane potential prior AP (initial $\mathrm{Vm}$ : iVm). For a RMP of $-60 \mathrm{mV}$, an after depolarization ( $\mathrm{ADP}$, a $\Delta \mathrm{Vm}$ positive to $\mathrm{iVm}$ ) is observed in control condition $+10 \mathrm{~ms}$ after the peak of the AP. For a RMP of $-50 \mathrm{mV}$, an after hyperpolarization (AHP, a $\Delta \mathrm{Vm}$ negative to $\mathrm{iVm}$ ) is observed in control condition after the peak of the AP. A fast and a moderate component of AHP (mAHP, at $+100 \mathrm{~ms}$ after the AP peak) are distinguished. B) Representative spontaneous AP recorded from CA3 pyramidal cell under pilocarpine condition at $-50 \mathrm{mV}$ in WT (left) or in GluK2-cKO neurons (right). An ADP is observable in GluK2-cKO CA3 but not in WT pyramidal cells at $+10 \mathrm{~ms}$. A small mAHP is observed at $+100 \mathrm{~ms}$ after the 
835 AP peak. C) Bar plot combined of scatter values from individual neurons of the $\Delta \mathrm{Vm}$ at $+10 \mathrm{~ms}$

836 after the AP peak. The $\Delta \mathrm{Vm}$ were calculated from all spontaneous APs, whatever iVm, and

837 averaged per cell (upon pilocarpine treatment). In average a positive $\Delta \mathrm{Vm}$ is observed in both

838 WT and GluK2-cKO CA3 but the amplitude is larger in GluK2-cKO CA3 neurons. D) Bar plot 839 combined of scatter values from individual neurons of the $\Delta \mathrm{Vm}$ at $+100 \mathrm{~ms}$ after the AP peak.

840 The $\Delta \mathrm{Vm}$ were calculated from all spontaneous $\mathrm{APs}$, whatever $\mathrm{iVm}$, and averaged per cell

841 (upon pilocarpine treatment). In average a negative $\Delta \mathrm{Vm}$ (different than 0 ) is observed in WT

842 but not in GluK2-cKO CA3 neurons. E, F) $\Delta \mathrm{Vm}$ plotted in function of $\mathrm{iVm}$ at +10 (E) or +100

843 (F) $\mathrm{ms}$ after the AP peak. Whereas a positive $\triangle \mathrm{Vm}(\mathrm{ADP})$ is observed below $-55 \mathrm{mV}$ in all 844 conditions, this ADP is observed above $-55 \mathrm{mV}$ only in GluK2-cKO CA3 neurons (E). A 845 negative $\Delta \mathrm{Vm}(\mathrm{AHP})$ is observed above $-45 \mathrm{mV}$ in $\mathrm{WT}$ but not GluK2-cKO CA3 neurons $(\mathrm{F})$.

\section{Figure 7 - Co-expression of GluK2 and Kv7.2 in stratum lucidum}

847 A) GluK2/K3 (top panels) and Kv7.2 (bottom panels) immunoreactivities in conjunction with 848 EGFP expression under Thy1 promoter showing the pattern of expression of these proteins in 849 the hippocampus. The presence of GluK2/K3 and Kv7.2 subunit in the stratum lucidum 850 indicates association of both channels with mossy fiber pathway. The expression profile of 851 both proteins in the hippocampus is presented in the graph as the average flourescence 852 intensity within distinct regions of CA3 (stratum radiatum, stratum lucidum, and stratum 853 pyramidale) normalized to stratum radiatum-derived average fluorescence (graph). B) Single 854 confocal plane images and 3D reconstructions of image stacks demonstrate colocalization of 855 M-channel with giant mossy fiber boutons (left panels) and thorny excrescence (right panels). 856 Localization of Kv7.2 in both pre- and postsynaptic compartments suggests co-expression of 857 KARs and M-channel at mossy fiber synapses. 
Kainate $20 \mathrm{mg} / \mathrm{kg}$

GluK1 BI6

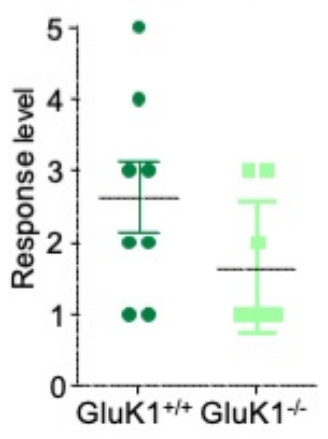

B

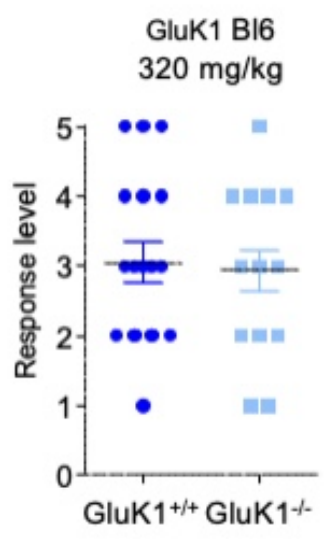

C
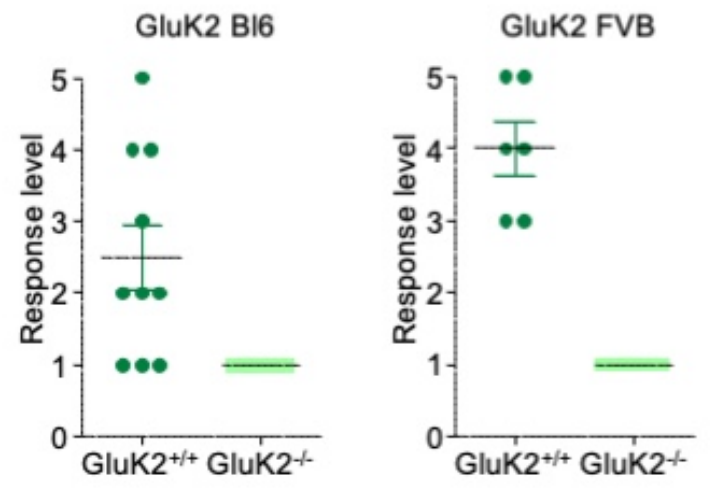

Pilocarpine
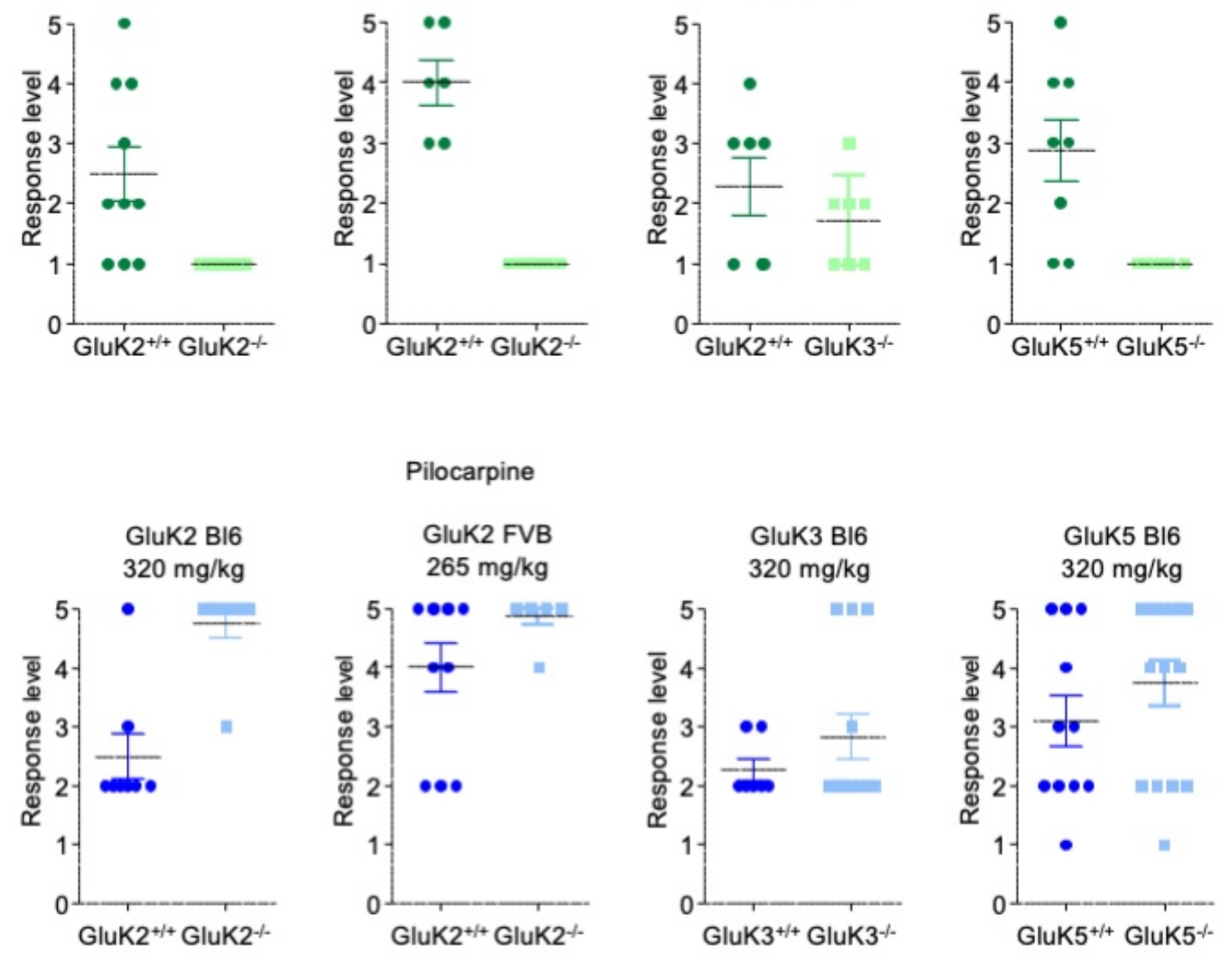

GluK5 BI6

PTZ

GluK1 BI6 $55 \mathrm{mg} / \mathrm{kg}$

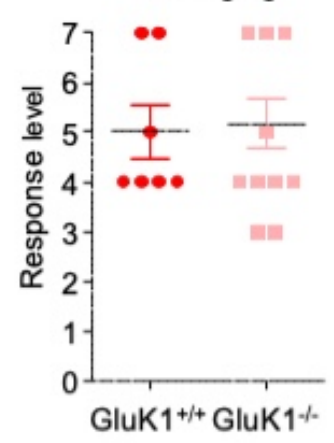

GluK2 BI6 $55 \mathrm{mg} / \mathrm{kg}$

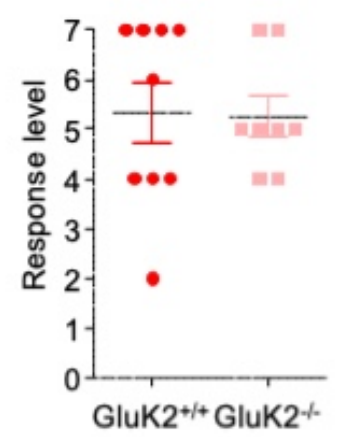

GluK2 FVB $45 \mathrm{mg} / \mathrm{kg}$

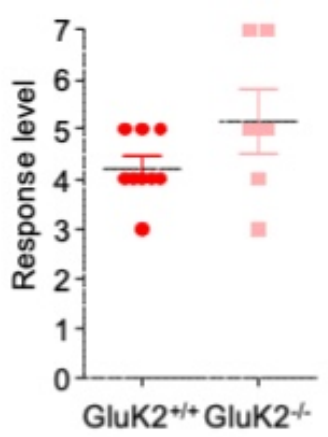

GluK3 BI6 $55 \mathrm{mg} / \mathrm{kg}$

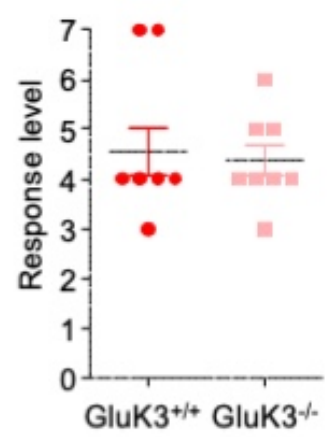

GluK5 BI6 $320 \mathrm{mg} / \mathrm{kg}$

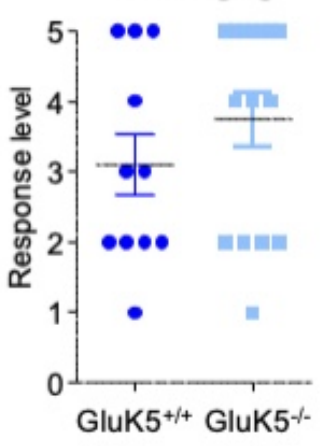

Figure 1 


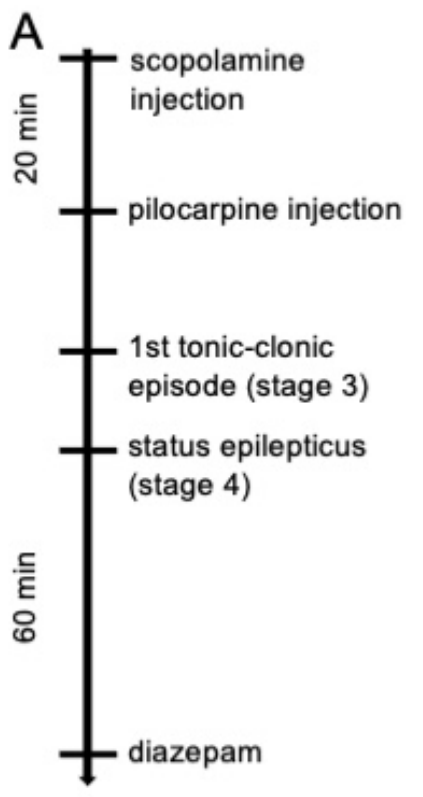

B1

- GluK2 $^{+/+}$B2

- GluK2seizure onset

seizure onset pilocarpine $200 \mathrm{mg} / \mathrm{kg}$

$\mathrm{GluK2}^{+/+}$ GluK2--
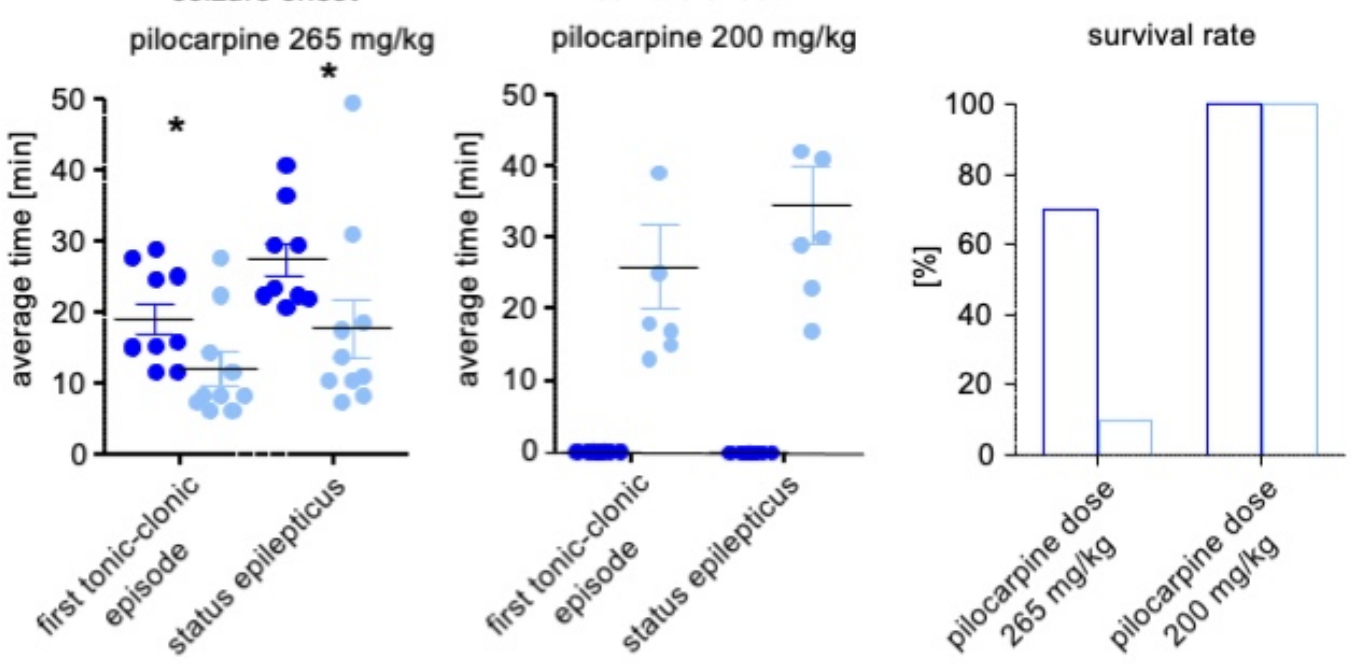

C
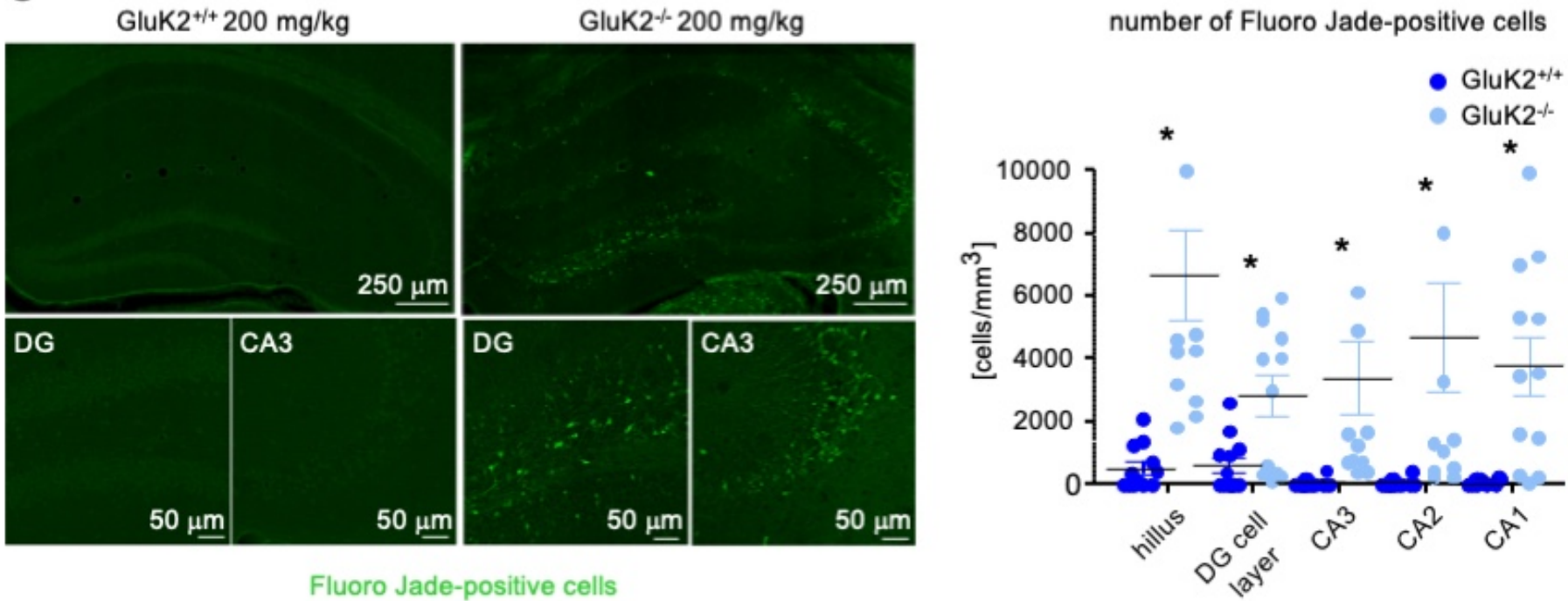

Fluoro Jade-positive cells

Figure 2 
A

GluK2--

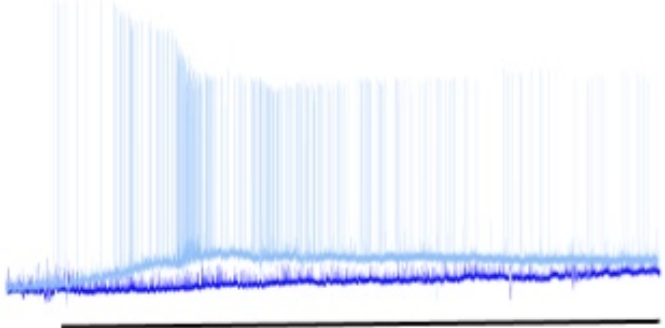

$10 \mu \mathrm{M}$ pilocarpine

B

$0.1 \mathrm{~Hz}$ and $3 \mathrm{~Hz}$

WT

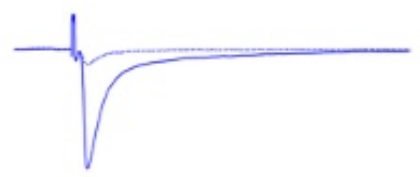

GluK2-cKO
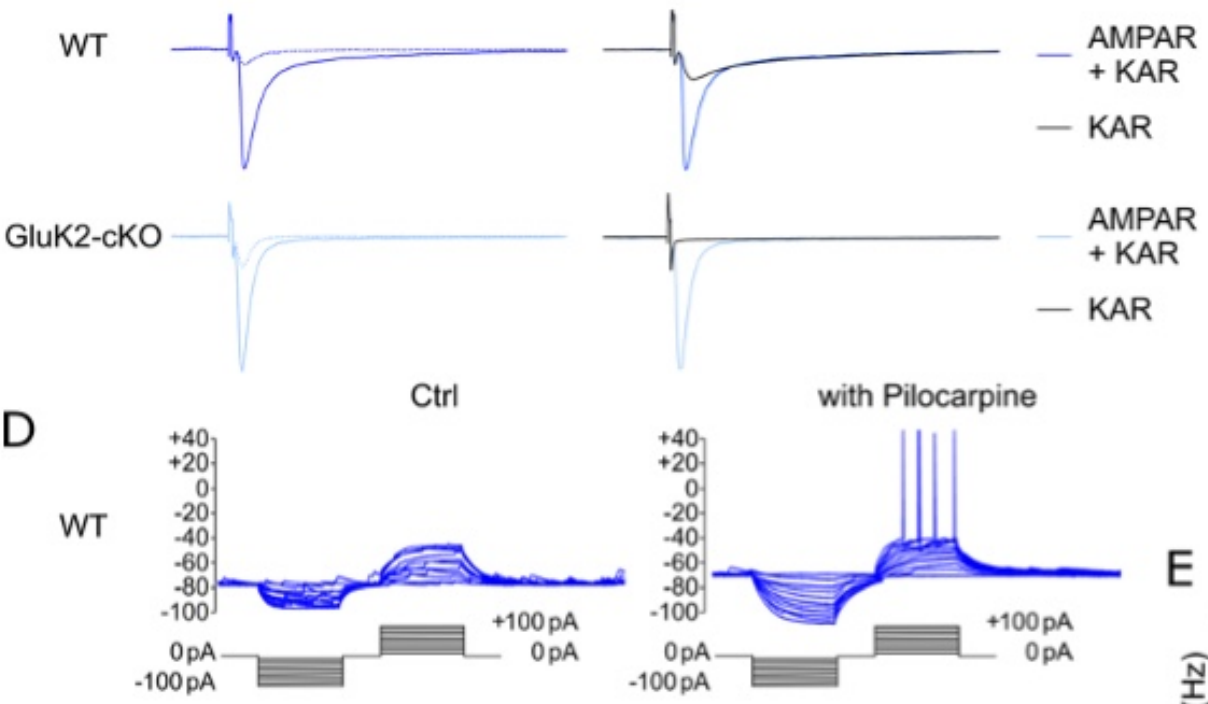

AMPAR

+ KAR

- KAR

with Pilocarpine
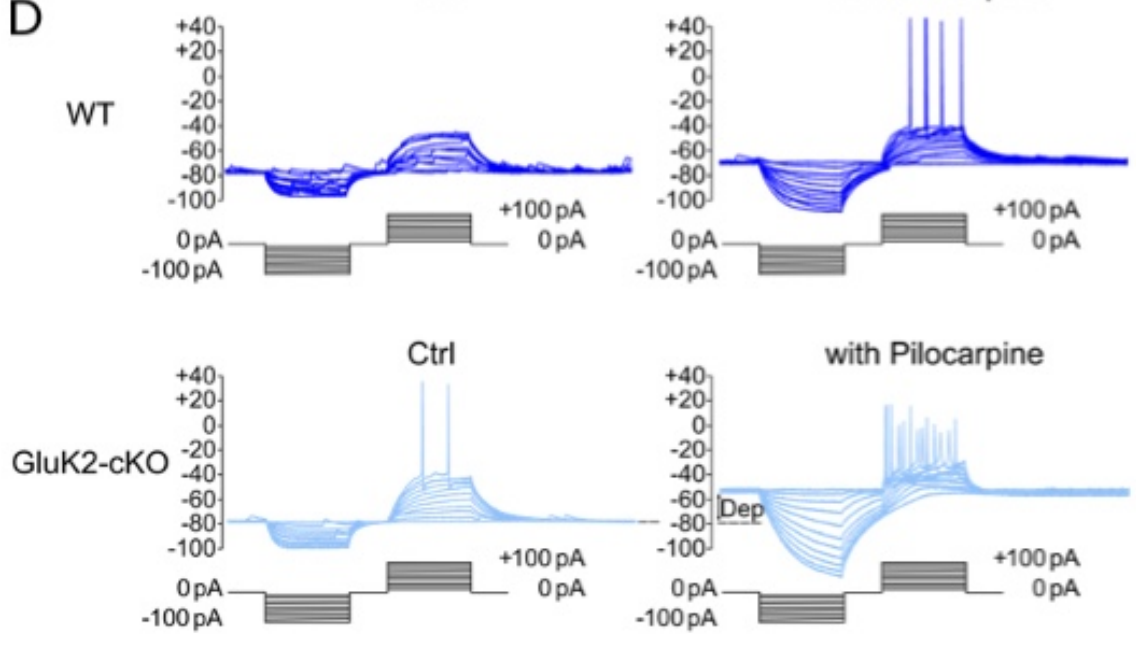

E

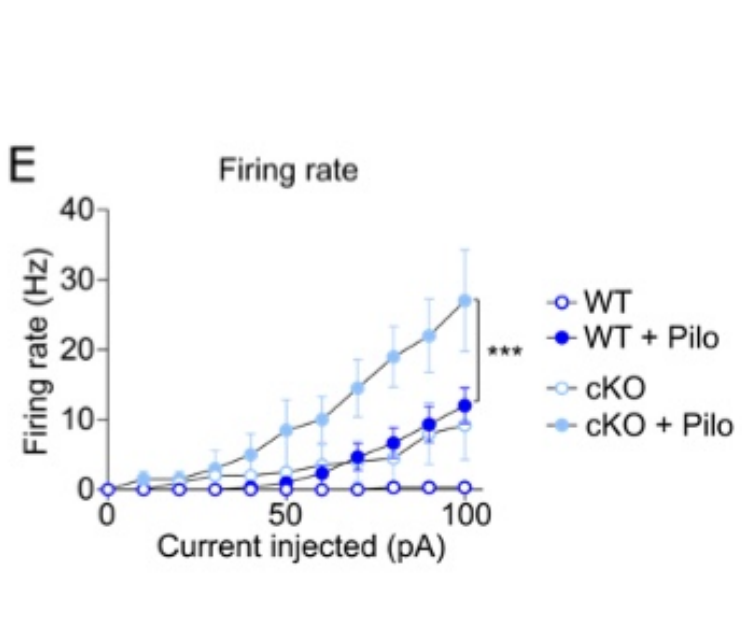

C KAR/AMPAR EPSCS

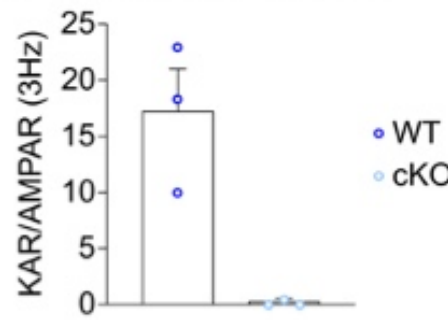

- GluK2 $2^{+/+}$

- GluK2\%
F

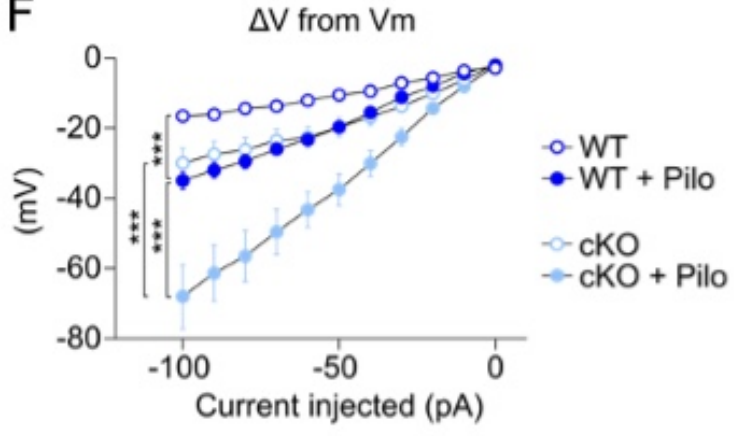

\section{G}

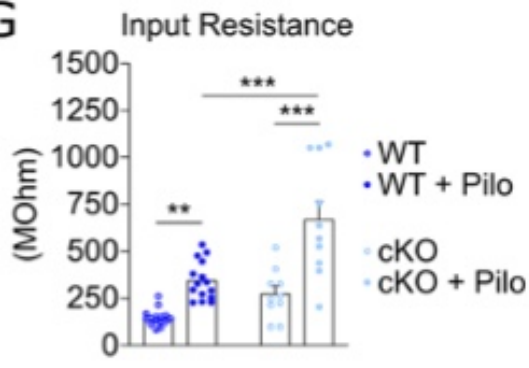

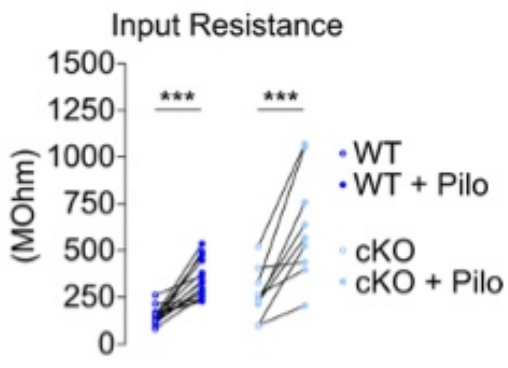

Figure 3 


$$
2.5 \mathrm{mM} \mathrm{K}^{+}
$$

$7.5 \mathrm{mM} \mathrm{K}^{+}$

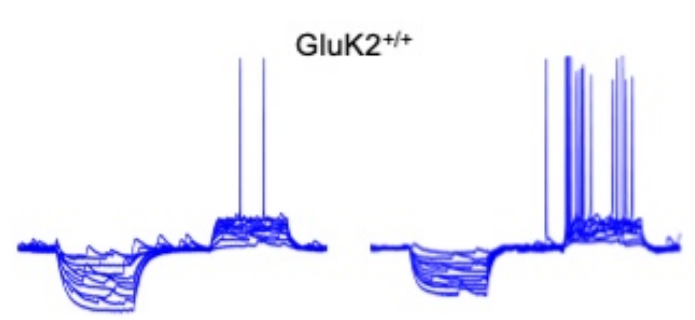

GluK2--

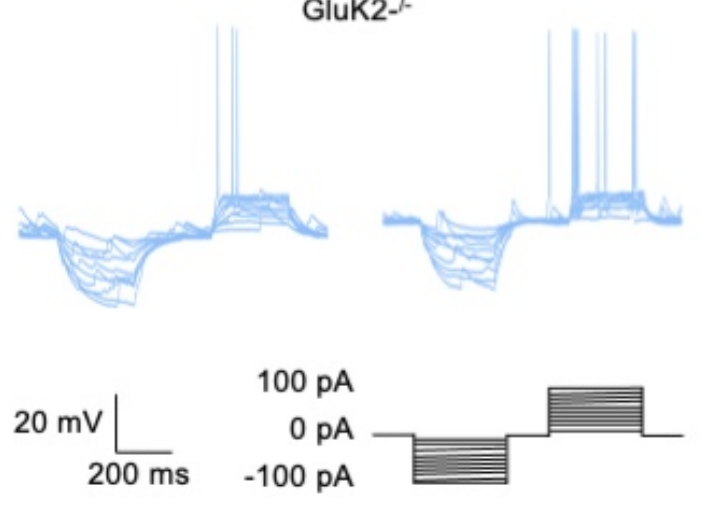

$2.5 \mathrm{mM} \mathrm{K}^{+}$
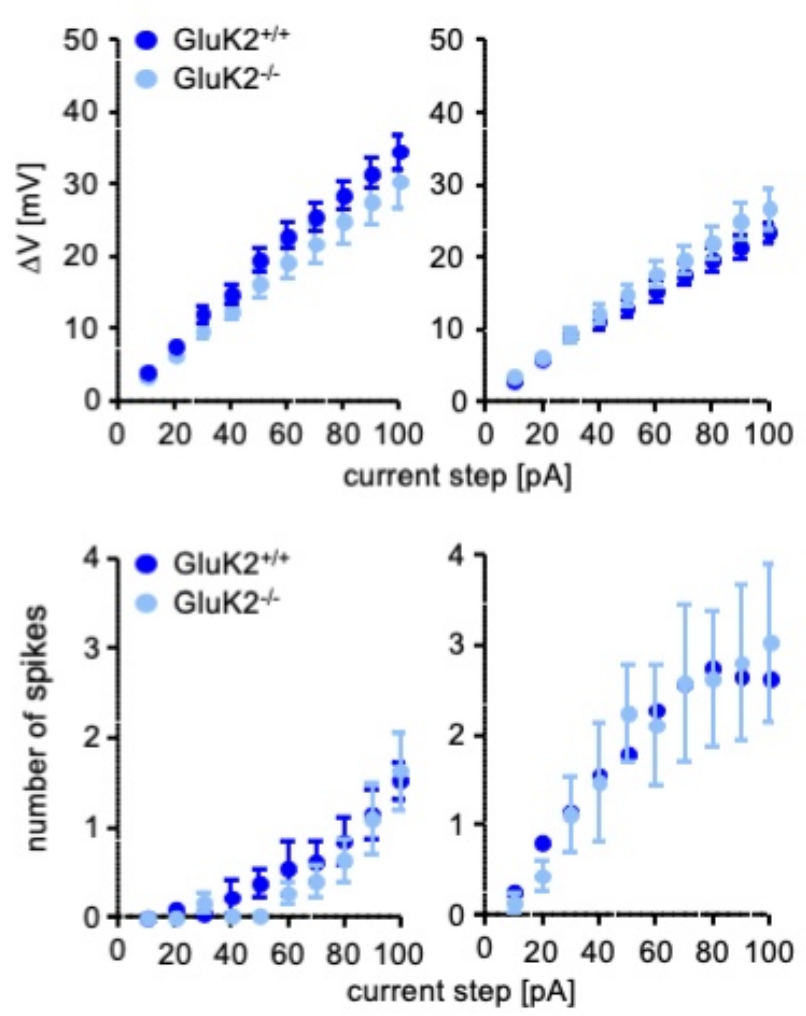

Figure 4 

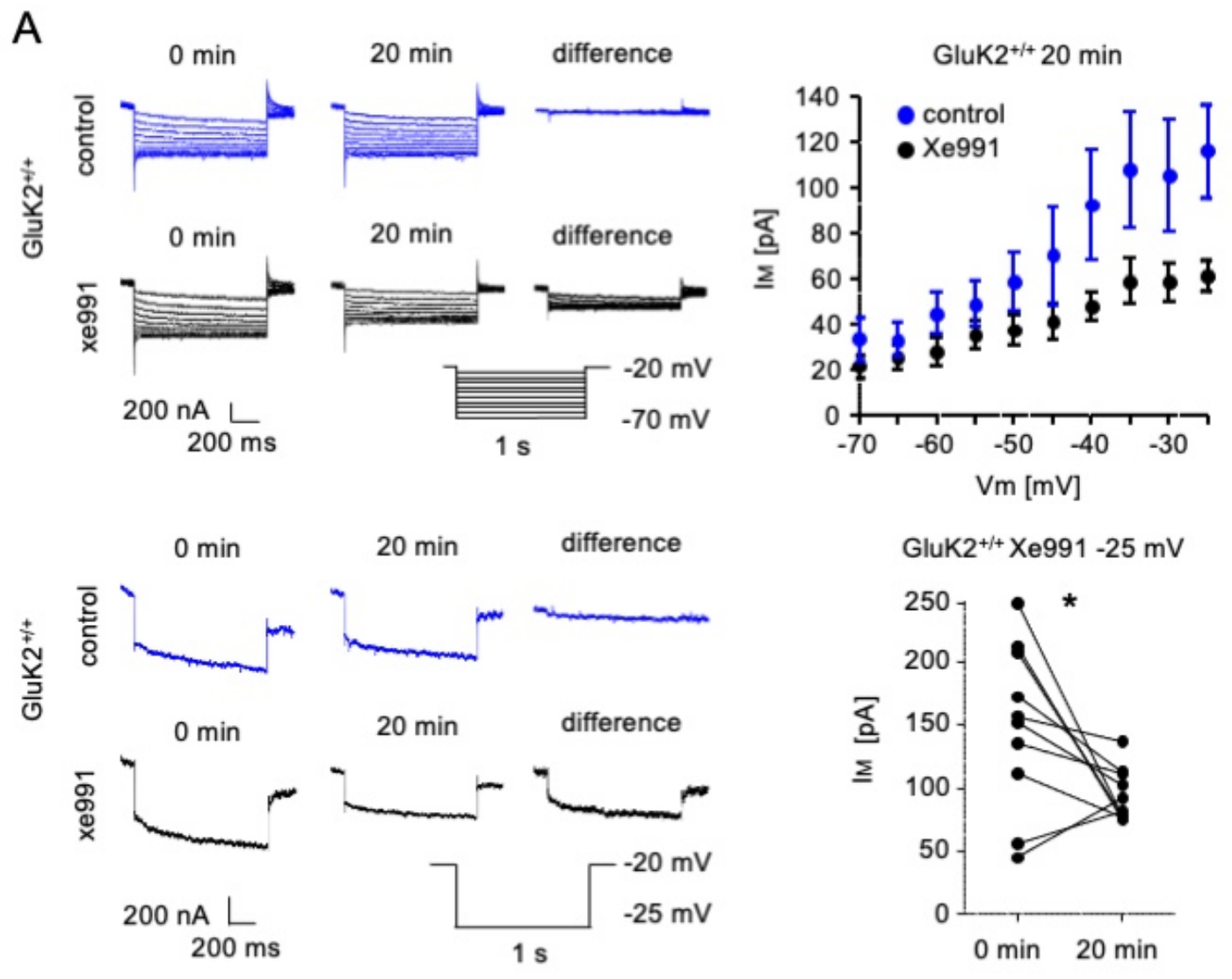

B
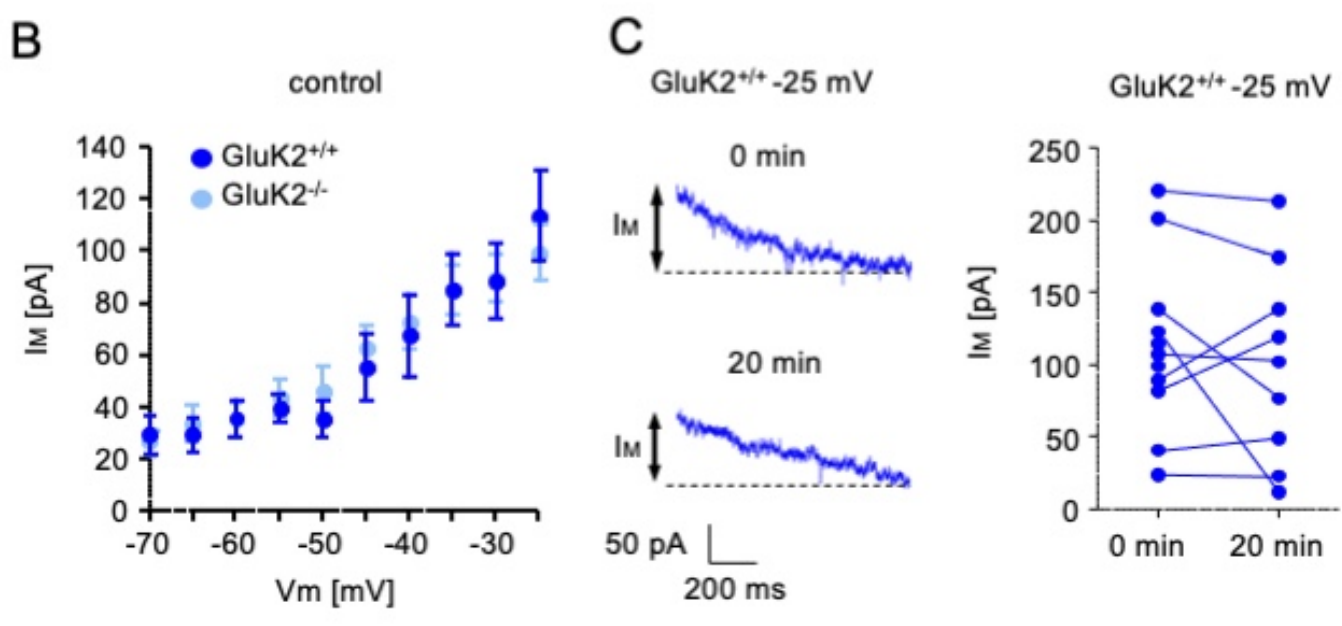

pilocarpine $10 \mu \mathrm{M} 20$ minutes

GluK2 ${ }^{-1-}-25 \mathrm{mV}$

GluK2 $^{-1-}-25 \mathrm{mV}$
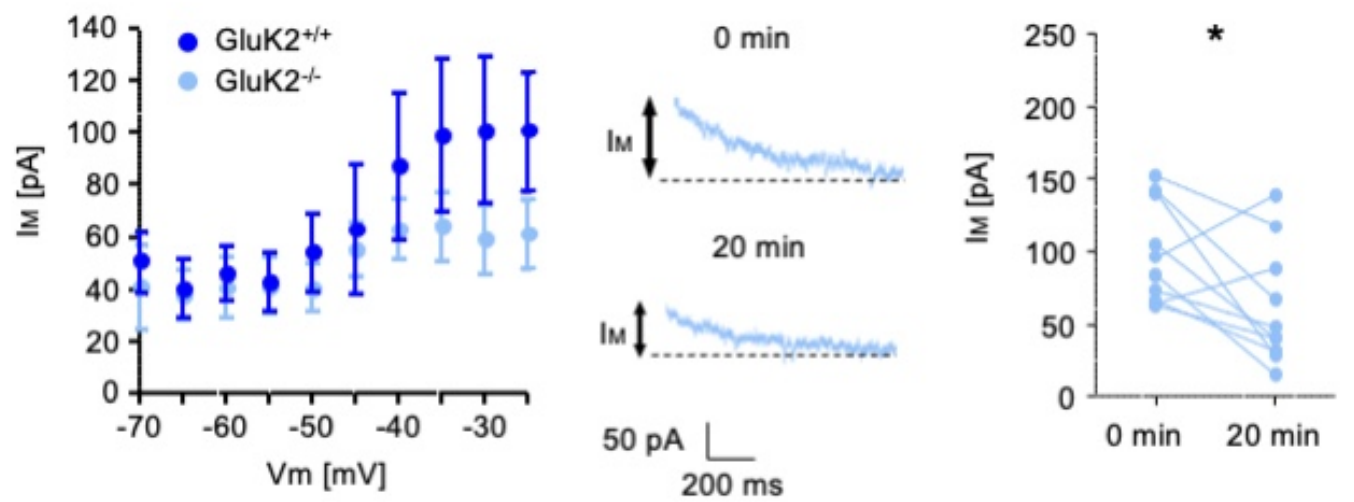

Figure 5 
A RMP: $-60 \mathrm{mV}$

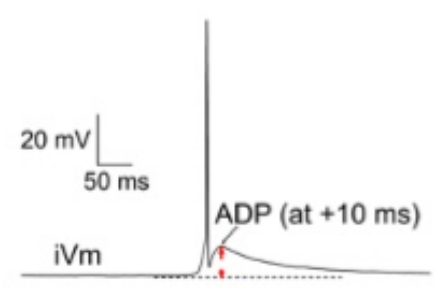

B WT (-50 mV; + Pilo)

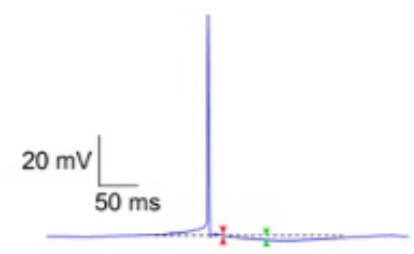

C $\Delta V \mathrm{~m}$ at $+10 \mathrm{~ms}$

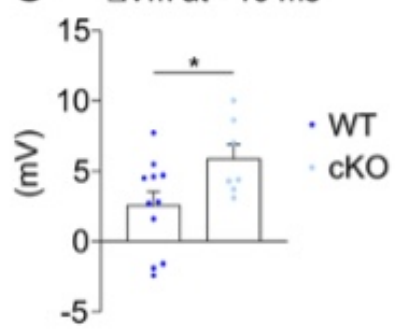

E
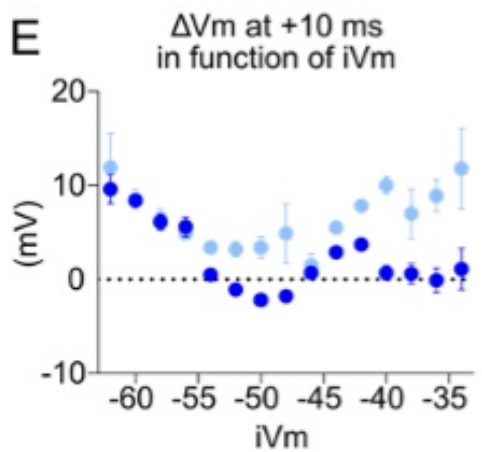

RMP: $-50 \mathrm{mV}$

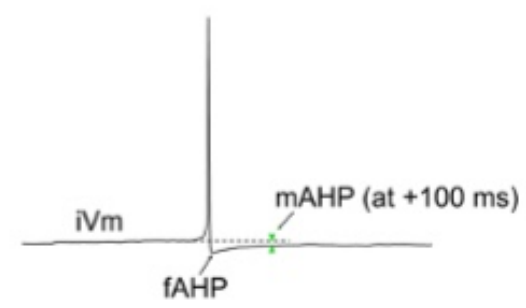

cKO (-50 mV; + Pilo)

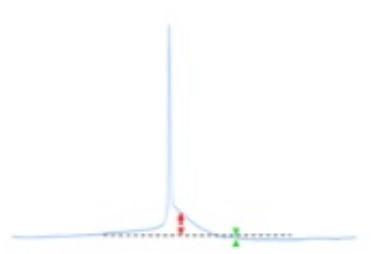

D $\Delta \mathrm{Vm}$ at $+100 \mathrm{~ms}$

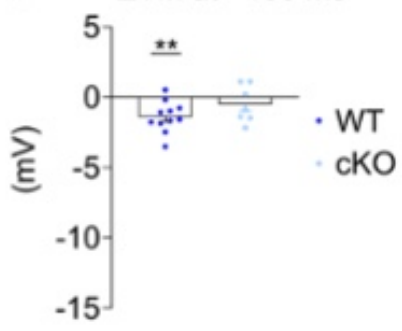

F $\quad \Delta \mathrm{Vm}$ at $+100 \mathrm{~ms}$

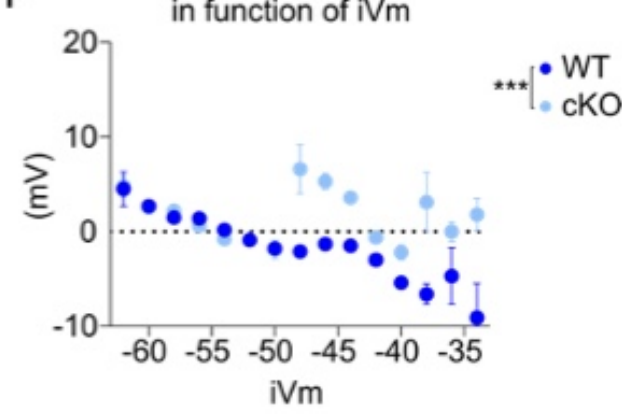

Figure 6 
A

Hippocampus

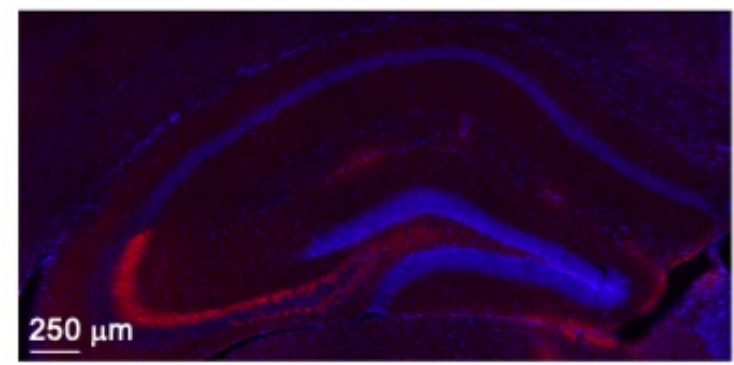

GluK2/K3 immunoreactivity

dapi

CA3 region of hippocampus

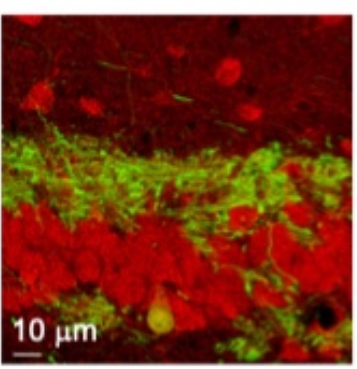

Kv7.2 immunoreactivity mossy fiber pathway

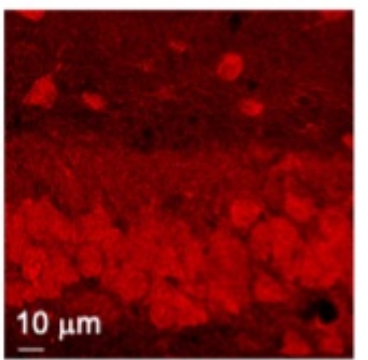

Kv7.2 immunoreactivity

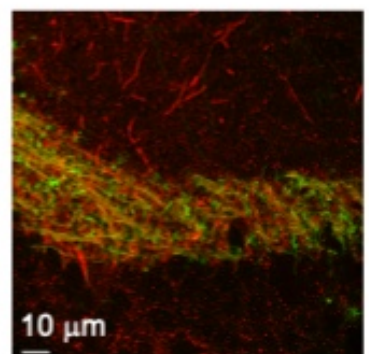

GluK2/K3 immunoreactivity

mossy fiber pathway

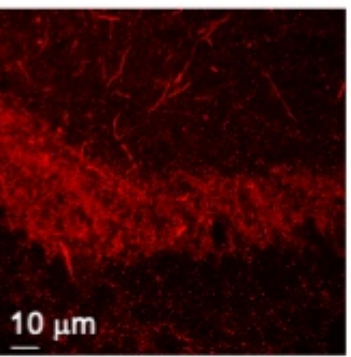

stratum

radiatum

stratum

lucidum

stratum

pyramidale

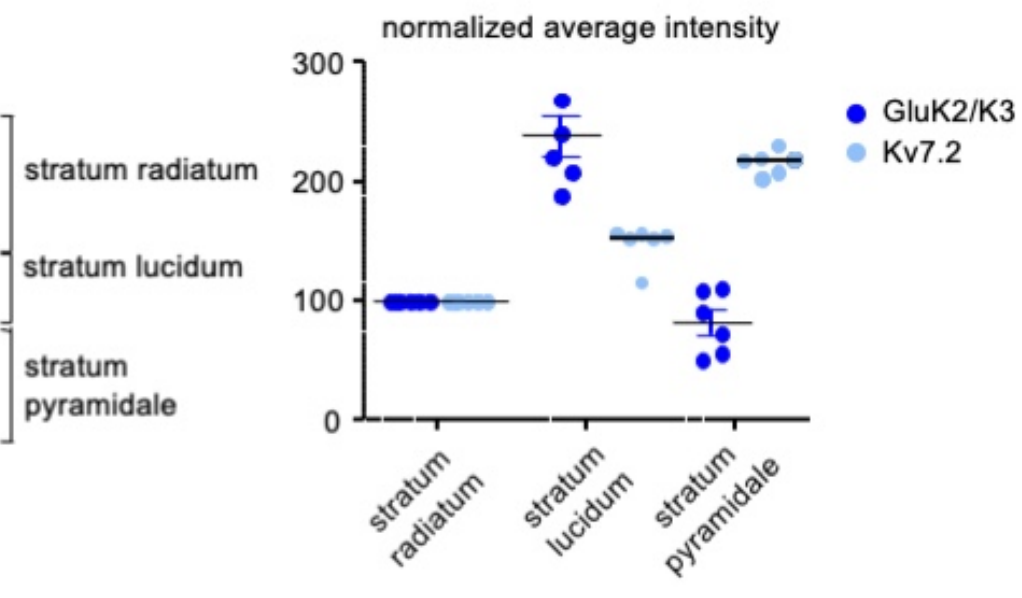

B

Mossy fiber bouton

single confocal plane

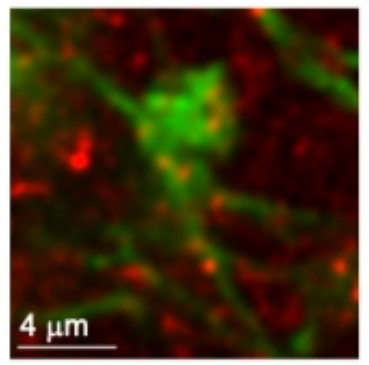

Kv7.2 immunoreactivity giant bouton
3D reconstruction

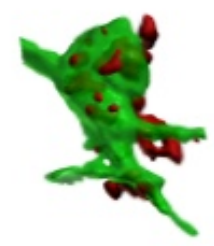

Kv7.2 immunoreactivity giant bouton

Thorny excrescence

single confocal plane

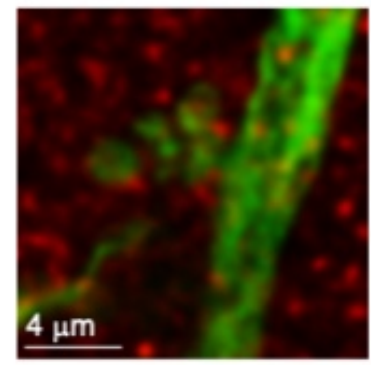

Kv7.2 immunoreactivity thorny excrescence
$3 \mathrm{D}$ reconstruction

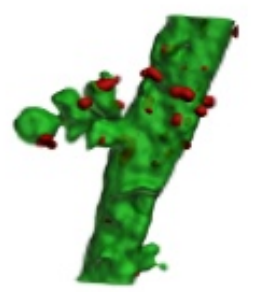

Kv7.2 immunoreactivity thorny excrescence

Figure 7 